\title{
Devices for In situ Development of Non-disturbed Oral Biofilm. A Systematic Review
}

\author{
Isabel Prada-López ${ }^{1}$, Víctor Quintas ${ }^{1}$, Carlos Vilaboa ${ }^{2}$, David Suárez-Quintanilla ${ }^{1}$ and \\ Inmaculada Tomás ${ }^{1 *}$
}

${ }^{1}$ Oral Sciences Research Group, Special Needs Unit, School of Medicine and Dentistry, Universidade de Santiago de Compostela, La Coruña, Spain, ${ }^{2}$ Dental Prosthesis Laboratory, School of Medicine and Dentistry, Universidade de Santiago de Compostela, La Coruña, Spain

\section{OPEN ACCESS}

Edited by:

Thomas Dandekar,

University of Würzburg, Germany

Reviewed by:

Alpdogan Kantarci,

Forsyth Institute, USA

Nick Stephen Jakubovics,

Newcastle University, UK

Giovanni Di Bonaventura,

"G. D'Annunzio" University of

Chieti-Pescara, Italy

*Correspondence:

Inmaculada Tomás

inmaculada.tomas@usc.es

Specialty section:

This article was submitted to

Infectious Diseases,

a section of the journal

Frontiers in Microbiology

Received: 20 January 2016

Accepted: 23 June 2016

Published: 19 July 2016

Citation:

Prada-López I, Quintas V, Vilaboa C,

Suárez-Quintanilla $D$ and Tomás I

(2016) Devices for In situ Development

of Non-disturbed Oral Biofilm. A

Systematic Review.

Front. Microbiol. 7:1055.

doi: 10.3389/fmicb.2016.01055
Objective: The aim of this review was to assess the types of devices used for in situ development of oral biofilm analyzed microbiologically.

Materials and Methods: A systematic search of the literature was conducted to identify all in situ studies of oral biofilm which used an oral device; the Ovid MEDLINE and EMBASE databases complemented with manual search were used. Specific devices used to microbiologically analyze oral biofilm in adults were included. After reading of the selected full texts, devices were identified and classified according to the oral cavity zone and manufacturing material. The "ideal" characteristics were analyzed in every group.

Results: The search provided 787 abstracts, of which 111 papers were included. The devices used in these studies were classified as palatal, lingual or buccal. The last group was sub-classified in six groups based on the material of the device. Considering the analyzed characteristics, the thermoplastic devices and the Intraoral Device of Overlaid Disk-holding Splints (IDODS) presented more advantages than limitations.

Conclusions: Buccal devices were the most commonly used for the study of in situ biofilm. The majority of buccal devices seemed to slightly affect the volunteer's comfort, the IDODS being the closest to the "ideal" model.

Clinical Relevance: New devices for in situ oral biofilm microbiological studies should take into account the possible effect of their design on the volunteer's comfort and biofilm formation.

Keywords: biofilm, dental plaque, device design, in situ, splints

\section{INTRODUCTION}

The oral cavity contains hard as well as soft tissue surfaces, all of which are potentially available as susceptible areas for the development of oral biofilms (Newman and Wilson, 1999). A specialized model of oral biofilm is dental plaque, which has been defined as a community of microorganisms found on the tooth surface as a biofilm, embedded in a matrix of polymers of salivary and bacterial origin (Marsh, 1999).

Abbreviations: AcD, Acrylic Device; AcMD, Acrylic and Metal Device; CFU, Colony Forming Units; CLSM, Confocal Laser Scanning Microscope; DAPI, Diamidino-2-Phenylindole; FISH, Fluorescence in situ Hybridisation; IDODS, Intraoral Device of Overlaid Disk-holding Splints; LiD, Leeds in situ Device; MD, Metal Device; PICO, Patient/Population Intervention Comparsion Outcome; PL-Biofilm, Plaque-Like Biofilm; TPD, Thermoplastic Device. 
Biofilms are important, because some resident species contribute to the maintenance of oral health and other species have the potential to cause local or systemic disease (Newman and Wilson, 1999). In fact, they are involved in the appearance or evolution of most oral conditions, such as caries and decalcifications, periodontal diseases or halitosis (Bowden and Li, 1997). In addition, they have direct impact on the regeneration and tissue healing after oral manipulation (Biofilm Club and Gilbert, 2007). Accordingly, a better knowledge of the oral biofilm characteristics results in the development of better strategies which are more effective in oral disease management (Arweiler et al., 2004). Apart from this, a study of the oral biofilm in individuals with systemic disease could help with the establishment of cause-effect relationships between dental plaque and specific systemic pathologies of possible oral origin ( $\mathrm{Li}$ et al., 2000).

The creation of in vitro biofilm models has contributed to significant advances in the study of oral diseases (Jefferson and Cerca, 2006; Kolenbrander et al., 2006; McBain, 2009; Nobbs et al., 2009; Palmer, 2010). However, their known limitations have caused the scientific community to recognize that the in vitro models might not generate a biofilm comparable to those found in situ (Wecke et al., 2000; Auschill et al., 2004, 2005; Watson et al., 2005; Al-Ahmad et al., 2007). For this reason, in vitro results must be interpreted cautiously (Auschill et al., 2004; AlAhmad et al., 2007; Hannig and Hannig, 2009). This affirmation establishes the need to develop models of biofilm in situ which could be analyzed ex vivo without distortion (Costerton et al., 1999; Palmer et al., 2001; Auschill et al., 2004; Hannig and Hannig, 2009).

In several in situ biofilm studies, the sample was recollected from the tooth surface for analysis with paper points (Charles et al., 2000), cotton rolls (Rosin et al., 2002) or scalers (Pan et al., 2000; Daneshmand et al., 2002; Konig et al., 2002; Fine et al., 2005; Loivukene et al., 2005; Arweiler et al., 2006; van der Mei et al., 2006; Al-Ahmad et al., 2010b). These procedures potentially disturb the delicate three-dimensional relationship between cells, the extracellular matrix and the substrate (Wecke et al., 2000; Wood et al., 2000; Dige et al., 2009a). This relation directly influences the biofilm behavior (Wood et al., 2000), which implies that a "non-disturbing" methodology must be applied in the study of any antimicrobial agent (Wood et al., 2000; Beyth et al., 2010). A "non-disturbing" methodology means that the biofilm is not altered during its formation, recollection, processing or analysis. In the literature, numerous artificial substrates were used instead of the natural surface of the teeth in order not to disturb the dental plaque at any stage of analysis; the resultant biofilm is known as Plaque-Like Biofilm (PL-Biofilm) (GarcíaCaballero et al., 2013; Tomás et al., 2013; Quintas et al., 2015b).

The literature defines several specific devices which were designed to form a PL-Biofilm in situ. In history, the first papers involving the use of devices for the formation of PL-Biofilm studied the decay, analyzing the demineralization effect (Ahrens, 1976; Koulourides et al., 1976; Ostrom and Koulourides, 1976; Minah and Chu, 1984). Some of these studies used the volunteer's own prosthesis (Koulourides et al., 1976; Minah and Chu, 1984) or their orthodontic appliances (Ostrom and Koulourides, 1976;
Jongsma et al., 2015) as artificial substrates for evaluating the oral biofilm activity. On the contrary, Ahrens (1976) designed a specific device in order to study this phenomenon. Later, in 1987, Nyvad et al. (Nyvad and Fejerskov, 1987a,b; Nyvad and Kilian, 1987) analyzed the characteristics of the in situ biofilm, formed on the device designed by Ahrens. Since then, the development of these devices has not stopped, but the format has changed from a bulky and poor esthetic to a discreet and comfortable one. One of the last devices to be designed was the "Intraoral Device of Overlaid Disk-holding Splints” (IDODS) (García-Caballero et al., 2013; Tomás et al., 2013; Quintas et al., 2015b), which uses a thermoplastic material with the intention of interfering as little as possible with the normal life of the volunteers. This evolutionary process left many different devices without any standardization or control. A deep analysis of the characteristics of each type of apparatus could help investigators in the field to choose one or another, depending on the aim of their study. In addition, the presentation of the data as advantages and disadvantages of each device could encourage the scientific community in the development of new devices, eventually reaching the "ideal" model. For these reasons, a systematic review of the quality and functionality of the different devices is proposed. The aim of this review was to assess, in adult population, the types of devices used for in situ development of oral biofilm analyzed microbiologically.

\section{MATERIALS AND METHODS}

A systematic review protocol was made in the planning stages according to the PRISMA checklist and approved by all authors. This review is reported according the PRISMA statement (Liberati et al., 2009). The PRISMA Checklist is attached as Table S1 in Supplementary Material.

\section{Focused Question}

This was the Patient/Population Intervention Comparison Outcome (PICO) question: In adult population, what are the advantages and disadvantages of the different types of devices that have been used for the growing of in situ oral biofilm?

The components of the PICO were:

Population: all adult volunteers (over 18 years old) wearing intraoral devices.

Intervention: type of device used for the growing of in situ oral biofilm.

Comparisons: between different types of devices.

Outcomes: advantages and disadvantages of each of the different devices.

\section{Eligibility Criteria}

All types of in situ studies on oral biofilm using a specific device (excluding prosthesis or orthodontic appliances) for its growth were considered eligible. The objective was to evaluate studies which took into account the characteristics of a non-disturbed biofilm of more than $4 \mathrm{~h}$ of maturation, analyzing its microbiological aspects (such as viability, thickness, structure or bacterial composition). Because of this, any studies 
which used devices to analyze specific actions of the biofilm on the tooth, such as demineralizations or decay, were excluded. Additionally, those which measured only biochemical aspects (fluoride concentration, $\mathrm{pH}$, etc.) in the oral biofilm were also excluded. The search was limited to humans and in vivo or in situ studies. No language restrictions were included.

\section{Information Sources and Search Strategy}

The literature search for relevant articles was conducted using the electronic database OVID MEDLINE and OVID EMBASE, the date of the last update was 16th of June 2015. The search strategy included the following search words:

- MeSH terms in all trees/subheadings: "dental plaque," "biofilms," and "splints."

- Keywords for dental plaque and biofilm: "dental plaque," "dental deposit*," "biofilm*," "biofouling," and "oral ADJ bacteria."

- Keywords for splints: "appliance*," "stent*," "splint*," "ferule*, "device*," "apparatus," "mechanism*," and "gadget*."

The same search strategy was used in the OVID EMBASE database, adapting the MeSH terms. Manual search was done by the reviewers after checking the reference lists of the relevant studies.

\section{Study Selection, Data Collection Process, and Data Items}

Study selection was conducted independently by two reviewers (IP-L and VQ) in the following stages: (1) initial screening of potentially suitable titles and abstracts meeting the inclusion criteria and (2) screening of the full texts identified as possibly relevant in the initial screen. The assistance of translators was sought for studies that were not in English.

Data were extracted using predefined data extraction forms including type of device, localization, substrate, number of participants, biofilm age, microbiological technique to analyze the biofilm, volunteer experience and removal and retention of the substrate.

Disagreements between reviewers were solved through discussion and consensus Kappa index at the first stage was 0.93 and 0.90 at the second stage. A difficulty in the systematic review was the poor description of a device or the absence of correlation between the description and the photographs presented. When doubts appeared, author contact was required. In studies where author contact was not successful and it was not possible to achieve an agreement in the type of device used, the decision was the exclusion.

\section{Summary Measures and Synthesis Results}

After reading the full text, descriptive summary analyses were reported, following systematic review guidelines (Mulrow et al., 1997). Because of the nature of this review a meta-analysis was not performed. The selected papers were classified in regard to the type of device used. The different apparatus found were divided into three categories, according to their design: palatal devices, lingual devices and buccal devices. This classification responds to the zone in which the device was placed within the oral cavity. In buccal devices, a second subdivision was made according to their material. As a result, six buccal device groups were obtained: Acrylic Device (AcD), Leeds in situ Device (LiD), Acrylic and Metal Device (AcMD), Metal Device (MD), Thermoplastic Device (TPD) and Intraoral Device of Diskholding Splints (IDODS). All of the papers which used a device made completely from acrylic were classified in the "AcD group." Papers which used a device bonded directly to the tooth formed the "LiD group"; those which used a device made of metal and acrylic were classified into the "AcMD group"; when a device made completely of metal was used, they were grouped as "MD group." Studies including a device made of one thermoplastic sheet were classified in the "TPD group" and, finally, those devices made of two sheets of thermoplastic material formed the "IDODS group."

Fourteen important qualities and characteristics of the ideal device were standardized by the authors for the analysis of each apparatus. The first eight questions were focused on the technical characteristics, the next three questions investigated the influence of the device on the volunteer's comfort and the final three questions were about manufacturing, placement and economic cost (Table 1).

\section{RESULTS}

\section{Study Selection}

The degree of agreement between reviewers was more than $97 \%$ at the first and second stages. After the initial search and removing duplications, 787 papers were found. When the titles and abstracts were read, the reviewers selected 127 papers. Following text screening, 16 papers were excluded due to the use of the patient's prosthesis or orthodontic devices, lack of information about the device or other factors, such as not analyzing the biofilm microbiologically or including population

TABLE 1 | The fourteen characteristics of the ideal "biofilm in situ device" classified in three main dimensions: technical, volunteer's comfort and economic.

\begin{tabular}{ll}
\hline TECHNICAL DIMENSION & \\
1 & Teeth pre-treatment is not necessary \\
2 & Specific teeth are not necessary \\
3 & No accidental unsticking \\
4 & Allows eating \\
5 & Easy withdrawal by the volunteer \\
6 & Easy withdrawal of the sample \\
7 & No contact with cheek /tongue \\
8 & Allows salivary flow through the splint \\
VOLUNTEER'S COMFORT DIMENSION \\
9 & Allows good oral hygiene \\
10 & Good aesthetic \\
11 & Little bulky \\
ECONOMIC DIMENSION & \\
12 & Adaptable on the 1st appointment \\
13 & Easy placement at 1st time \\
14 & Inexpensive material \\
\hline
\end{tabular}


of less than 18 years of age. Finally, 111 papers were selected for assessment of the full text (Figure 1, PRISMA flow Diagram).

All of these were written in English, with the exception of one which was in Chinese.

\section{Study Characteristics}

All characteristics of the selected studies are in the Data Sheet 1 in Supplementary Material. Following, there is a description of the most noticeable characteristics.

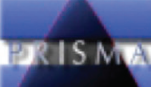

\section{PRISMA 2009 Flow Diagram}

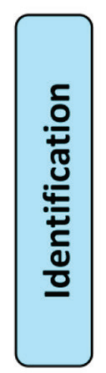

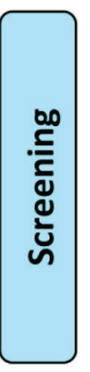
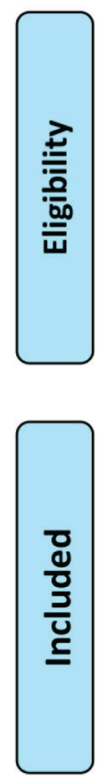

Records identified through

database searching

$(n=1027)$
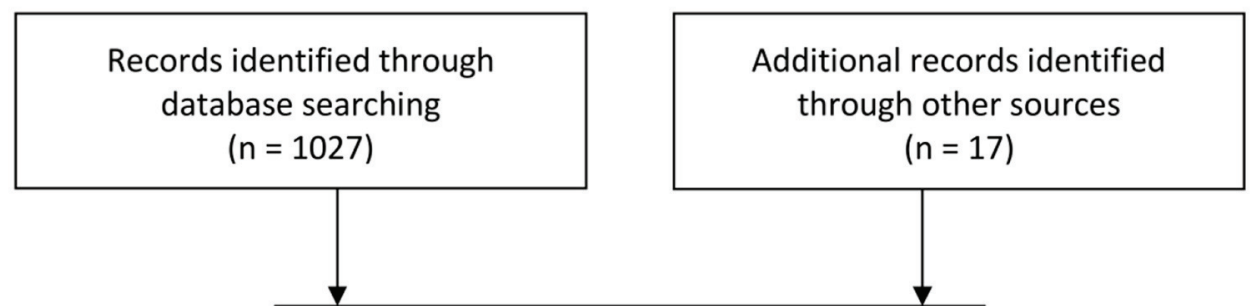

Records after duplicates removed

$(n=787)$
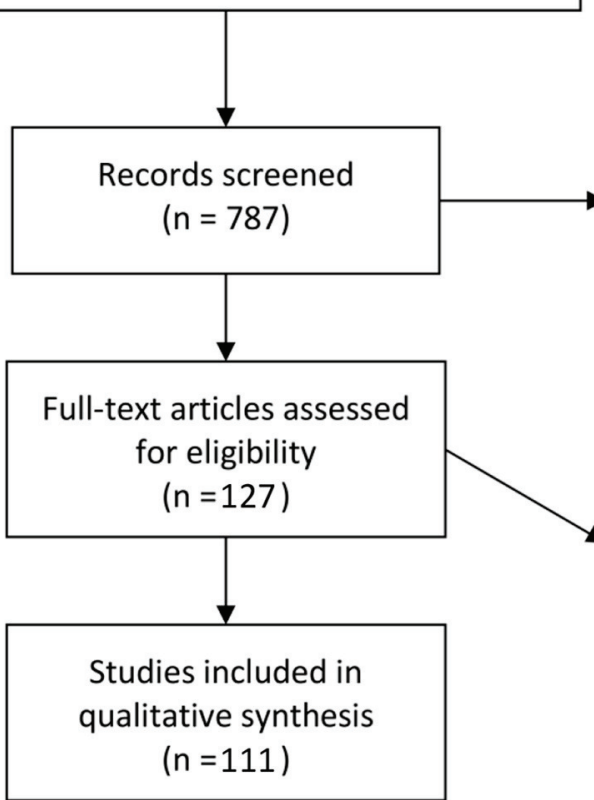

Records excluded $(n=660)$

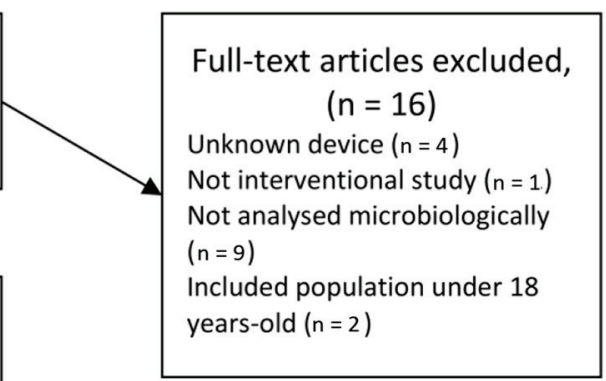

FIGURE 1 | PRISMA 2009 Flow Diagram. 


\section{Types and Number of Substrates}

The most commonly used substrates for the development of in situ oral biofilm have been the human (Creanor et al., 1986; Strassler et al., 1986; Nyvad and Fejerskov, 1987a,b; Nyvad and Kilian, 1987; Jenkins et al., 1988; Nyvad and Fejerskov, 1989; Macpherson et al., 1990, 1991; Robinson et al., 1997; Wood et al., 1999, 2000, 2002; Arai et al., 2000; Cury et al., 2001; Shore et al., 2001; Palmer et al., 2003; Kato et al., 2004; Pecharki et al., 2005; Ribeiro et al., 2005; Diaz et al., 2006; Korytnicki et al., 2006; Robinson et al., 2006; Arthur et al., 2007; Chalmers et al., 2007; Paes Leme et al., 2008; Gameiro et al., 2009; de Mazer Papa et al., 2010; von Ohle et al., 2010; Brambilla et al., 2012; Cochrane et al., 2012; Kato et al., 2012; Teixeira et al., 2012; Pierro et al., 2013) and bovine enamels (Strassler et al., 1986; Hannig, 1997, 1999a,b; Giertsen et al., 2000; Auschill et al., 2001; Jentsch et al., 2002; Tenuta et al., 2003; Paes Leme et al., 2004; Al-Ahmad et al., 2007, 2009, 2010a,c, 2013; Hannig et al., 2007b, 2013b,c; Arweiler et al., 2008; Jung et al., 2010; Brighenti et al., 2012; Kensche et al., 2013; Melo et al., 2013; Arweiler et al., 2014; Bittar et al., 2014; Grychtol et al., 2014) (in this order). Moreover, the number of substrates used in the different devices varied between one (Auschill et al., 2001) and 16 (Hannig, 1997, 1999a,b).

\section{Biofilm Age}

This went from $4 \mathrm{~h}$ (Nyvad and Fejerskov, 1987a,b; Nyvad and Kilian, 1987; Zucchelli et al., 1998; Fine et al., 2000; Zucchelli et al., 2000; Diaz et al., 2006; Palmer et al., 2003; Beyth et al., 2010; Claro-Pereira et al., 2011; Kensche et al., 2013; Sreenivasan et al., 2004) to 8 weeks (Benelli et al., 1993; He et al., 2013).

\section{Microbiological Techniques Used for In situ PL-Biofilm Analysis}

The most commonly used techniques in these studies are those based on visualizing the oral biofilm with fluorescence microscopes [both epifluorescence and Confocal Laser Scanning Microscope (CLSM)] (Benelli et al., 1993; Netuschil et al., 1998; Wood et al., 1999, 2000, 2002; Giertsen et al., 2000; Auschill et al., 2001, 2002, 2004, 2005; Palmer et al., 2003; Arweiler et al., 2004; Al-Ahmad et al., 2007, 2009, 2010a,c, 2013; Chalmers et al., 2007; Dige et al., 2007, 2009a,b; Arweiler et al., 2008; Hannig et al., 2013a,b,c; Beyth et al., 2010; Burgers et al., 2010; Dong et al., 2010; Gosau et al., 2010; Jung et al., 2010; von Ohle et al., 2010; Bremer et al., 2011; Gu et al., 2012; Rupf et al., 2012; García-Caballero et al., 2013; He et al., 2013; Kensche et al., 2013; Tomás et al., 2013; Arweiler et al., 2014; Grychtol et al., 2014; Padovani et al., 2015; Prada-López et al., 2015a,b; Quintas et al., 2015a,b) (45 studies), mainly combined with fluorescence in situ hybridization (FISH) and 4',6-diamidino-2-phenylindole (DAPI) for bacterial identification. In the case of studies aiming for the analysis of bacterial viability, fluorescence microscopes have usually been combined with staining dyes for live/dead bacterial identification such as SYTO 9/Propidium Iodide and Fluorescein Diacetate/Etidium Bromide.

Another common technique has been the Colony Forming Units (CFU) counting (Creanor et al., 1986; Strassler et al., 1986; Nyvad and Kilian, 1987; Jenkins et al., 1988; Macpherson et al., 1990, 1991; Benelli et al., 1993; Leonhardt et al., 1995; Robinson et al., 1997; Fine et al., 2000; Giertsen et al., 2000; Cury et al., 2001; Shore et al., 2001; Hara et al., 2003; Tenuta et al., 2003; Paes Leme et al., 2004; Sreenivasan et al., 2004; Pecharki et al., 2005; Ribeiro et al., 2005; Korytnicki et al., 2006; Schwarz et al., 2006, 2009; Arthur et al., 2007; Sennhenn-Kirchner et al., 2007; Gameiro et al., 2009; Lima et al., 2009; Sennhenn-Kirchner et al., 2009; Sousa et al., 2009; Sreenivasan et al., 2009; Al-Ahmad et al., 2010a; de Mazer Papa et al., 2010; Jung et al., 2010; von Ohle et al., 2010; Claro-Pereira et al., 2011; Brighenti et al., 2012; Teixeira et al., 2012; Melo et al., 2013; Pierro et al., 2013; Grychtol et al., 2014) (40 studies).

\section{Classification of the Papers According to the Devices} Palatal devices (Figures 2A,B; Benelli et al., 1993; Cury et al., 2001; Hara et al., 2003; Tenuta et al., 2003; Paes Leme et al., 2004; Pecharki et al., 2005; Ribeiro et al., 2005; Korytnicki et al., 2006; Schwarz et al., 2006, 2007, 2009; Arthur et al., 2007; Paes Leme
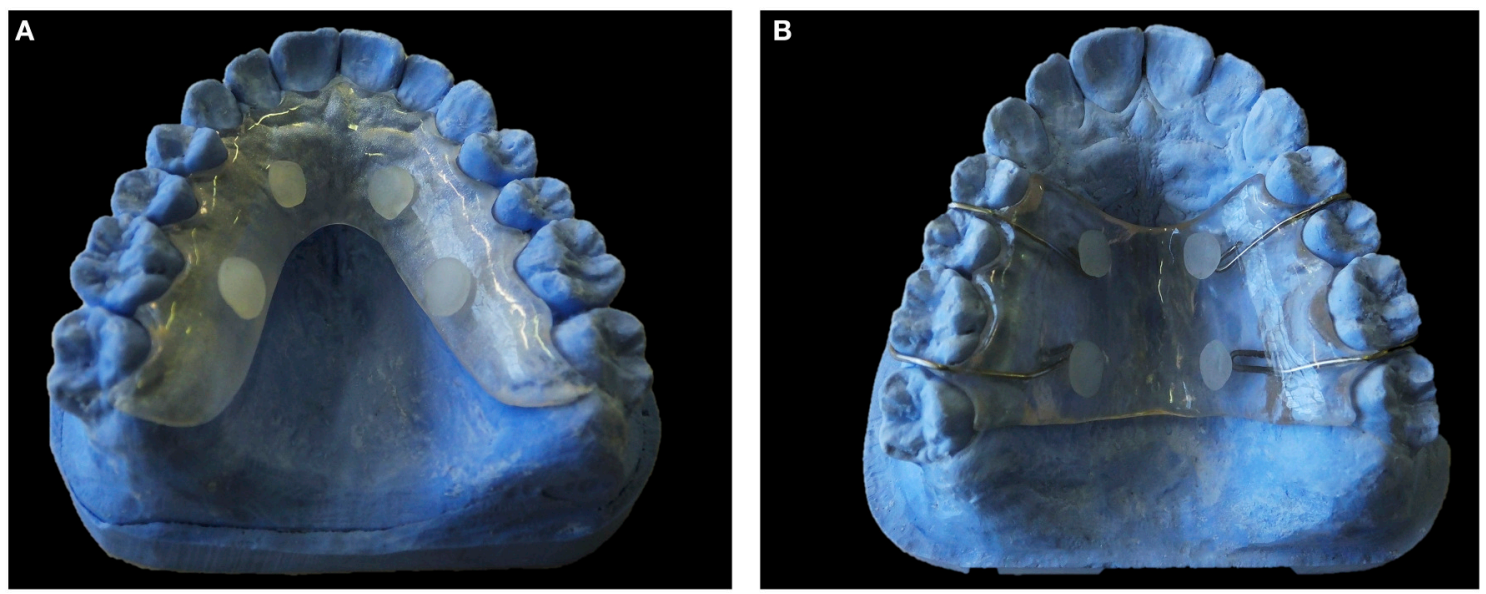

FIGURE 2 | Palatal Devices. (A) Model of acrylic palatal device. (B) Model of acrylic and metal palatal device. 
et al., 2008; Gameiro et al., 2009; Lima et al., 2009; Sousa et al., 2009; Beyth et al., 2010; de Mazer Papa et al., 2010; Brighenti et al., 2012; Cochrane et al., 2012; Teixeira et al., 2012; Melo et al., 2013; Pierro et al., 2013; Bittar et al., 2014; Padovani et al., 2015) were always exposed to contact with the tongue. To avoid this situation some authors included a plastic mesh (Cury et al., 2001). In lingual devices (Figure 3) (Creanor et al., 1986; Jenkins et al., 1988; Macpherson et al., 1990, 1991; Rasperini et al., 1998; Sreenivasan et al., 2004; Re et al., 2011), the biofilm grew between the device and the lingual gingiva. This protection against tongue contact produced a biofilm that grew in a different environment from the normal lingual biofilm attached to the surface of the teeth. The use of these devices has not been very extensive (only seven studies used them).

On the other hand, buccal devices have been used extensively, allowing the definition of six different groups: AcD (Figures 4A,B) (Nyvad and Fejerskov, 1987a,b, 1989; Nyvad and Kilian, 1987; Hannig, 1997; Netuschil et al., 1998; Hannig, 1999a,b; Fine et al., 2000; Auschill et al., 2001, 2002; Jentsch et al., 2002; Palmer et al., 2003; Scarano et al., 2003; Groessner-Schreiber et al., 2004; Diaz et al., 2006; Chalmers et al., 2007; Hannig et al., 2007b; Scotti et al., 2007; Grossner-Schreiber et al., 2009; Sreenivasan et al., 2009; Azevedo et al., 2012; Rehman et al., 2012; Do Nascimento et al., 2013; Nascimento et al., 2014), LiD (Figures 5A,B; Strassler et al., 1986; Robinson et al., 1997; Wood et al., 1999, 2000, 2002; Arai et al., 2000; Shore et al., 2001; Kato et al., 2004; Robinson et al., 2006; Dong et al., 2010; Kato et al., 2012; He et al., 2013), AcMD (Figures 6A,B; Rimondini et al., 1997; Zucchelli et al., 1998; Giertsen et al., 2000; Zucchelli et al., 2000; Arweiler et al., 2004; Auschill et al., 2004, 2005; Al-Ahmad et al., 2007, 2010a,c, 2013; Dige et al., 2007; Arweiler et al., 2008, 2014; Dige et al., 2009a,b; von Ohle et al., 2010; Bremer et al., 2011), MD

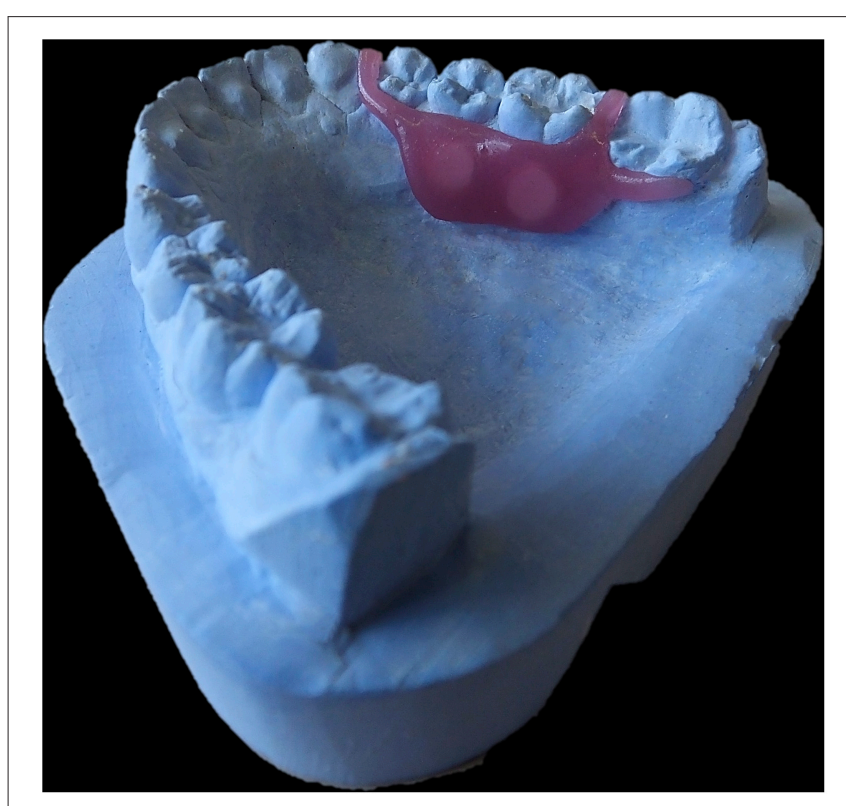

FIGURE 3 | Lingual Device. Model of an acrylic lingual device.
(Figure 7; Leonhardt et al., 1995; Simion et al., 1997), TPD (Figure 8; Sennhenn-Kirchner et al., 2007; Al-Ahmad et al., 2009; Sennhenn-Kirchner et al., 2009; Burgers et al., 2010; Gosau et al., 2010; Jung et al., 2010; Claro-Pereira et al., 2011; Brambilla et al., 2012; Gu et al., 2012; Rupf et al., 2012; Hannig et al., 2013b,c; Kensche et al., 2013; Grychtol et al., 2014) and IDODS (Figures 9A,B; García-Caballero et al., 2013; Tomás et al., 2013; Prada-López et al., 2015a,b; Quintas et al., 2015a,b). In the review process, another device was found, a device made completely of silicone used in only one paper (Giordano et al., 2011).

In summary, Tables 2, 3 show all of the papers which studied in situ biofilm, classified according to the type of device used. However, this classification was limited by the scant information some authors provided about the devices they used.

\section{Characteristics of Buccal Devices}

The evaluations of each buccal device group according to the ideal characteristics they should meet are presented in Table 4. The AcD and LiD were the buccal devices that showed more limitations than advantages. On the contrary, the TPD and IDODS presented more advantages than limitations.

\section{- Pre-Treatment of Specific Teeth}

The pre-treatment of teeth is only necessary in the LiD group; it needs from etching, bonding and a composite to be glued onto specific teeth (first and second molars).

\section{- Accidental Unsticking}

Accidental loss of samples has been found in the $\mathrm{LiD}, \mathrm{AcD}$, AcMD and MD groups. Conversely in TPD and IDODS groups no loss of specimens has been reported.

\section{- Eating and Chewing with the Device}

The LiD allows the user to eat whilst wearing it, without the need for its withdrawal, as happens with AcMD and MD. The AcD, TPD and IDODS do not permit chewing, because they cover the occlusal zone of the molars.

\section{- Withdrawal by the Volunteer}

All of the apparatus, with the exception of the LiD, can easily be withdrawn by the volunteer in order to perform their oral hygiene measures normally (according to the protocol of the study).

- Withdrawal of the Sample by the Investigator

The withdrawal of the sample from the $\mathrm{LiD}, \mathrm{AcD}$ and AcMD by the investigator is done with a forceps or a bracketremoving plier. On the other hand, in the TPD, the investigator must take the sample by its backside with tweezers (Burgers et al., 2010; Gosau et al., 2010) or remove the silicone and take the disk by the lateral sides (Jung et al., 2010). In the same way, the IDODS has a specific gap between the two sheets which permits the withdrawal of the disk by the lateral sides. 

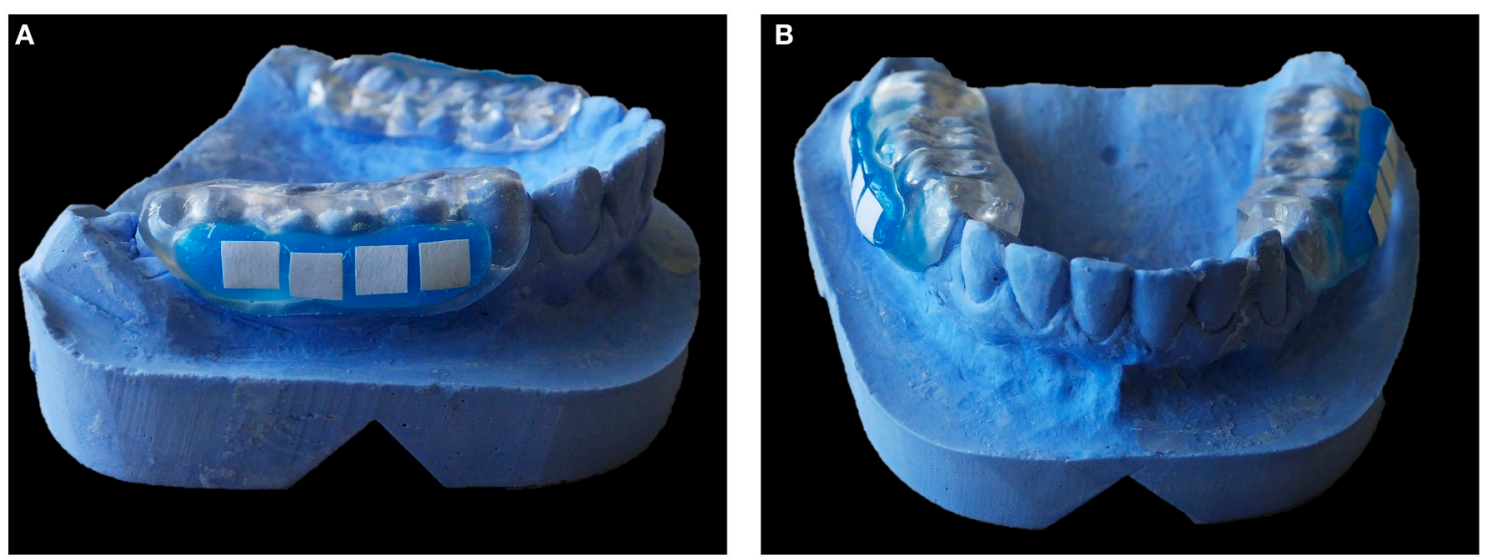

FIGURE 4 | Acrylic Device (AcD). (A) Lateral view. (B) Frontal view.
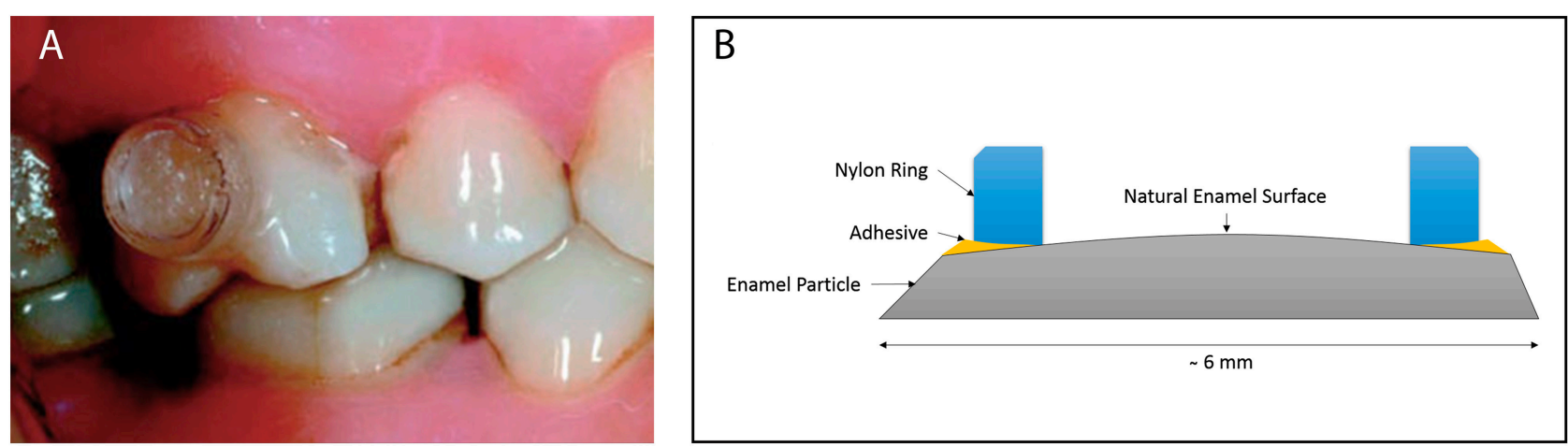

FIGURE 5 | Leeds in situ Device (LiD). (A) Intraoral image by Pessan et al. (2008) in Journal Appliance Oral Science. (B) Own design scheme.

- Contact with Cheek and Tongue

The TPD, MD and IDODS have a special framework (with composite in $\mathrm{MD}$ ) which protects the substrate from making contact with anything other than from the saliva or any other liquids inside the mouth (antiseptic agent). In the AcMD, the disk is located in a sheltered space between the tooth and the device, which protects the biofilm from contact with the cheek and tongue.

- Salivary Flow through the Splint

Only the IDODS allows salivary flow through it, leaving both sides of the disk exposed.

\section{- Volunteer's Comfort}

AcD are very voluminous, dramatically affecting the phonetics and the esthetics of the volunteers; the same is true for the metal used in the AcMD. Conversely, the $\mathrm{LiD}$ (situated in the posterior molar), the TPD and the IDODS (both made of transparent material) are less voluminous. For these reasons, they slightly affect the phonetics and the esthetics.

- Adaptability, Placement and Manufacturing Cost
Manufacturing processes for these devices are very diverse. All devices except the LiD need a plaster model of the volunteer to be made in order for the device to fit properly. The LiD, being a standard apparatus, does not need any type of individualisation prior to placement. Other devices such as AcD and TPD or the IDODS need a laboratory process, but their fabrication is simple and not too expensive. However, the AcMD and overall the MD (made of Cobalt and Chrome) requires a more complex laboratory process which increases the cost of the device.

In regard to the placement in mouth, there are also differences between the LiD and other devices, due to the fact that it must be placed in the clinic with the proper isolation and specific protocols, similar to those used in bracket bonding. However, all of the other devices are given to volunteers with the instructions for correct use, in the same way as if they were removable orthodontic retainers.

\section{DISCUSSION}

No previous reference was found to give the authors a base to work with the characteristics of the different devices. Given this circumstance, a list of fourteen important qualities and 

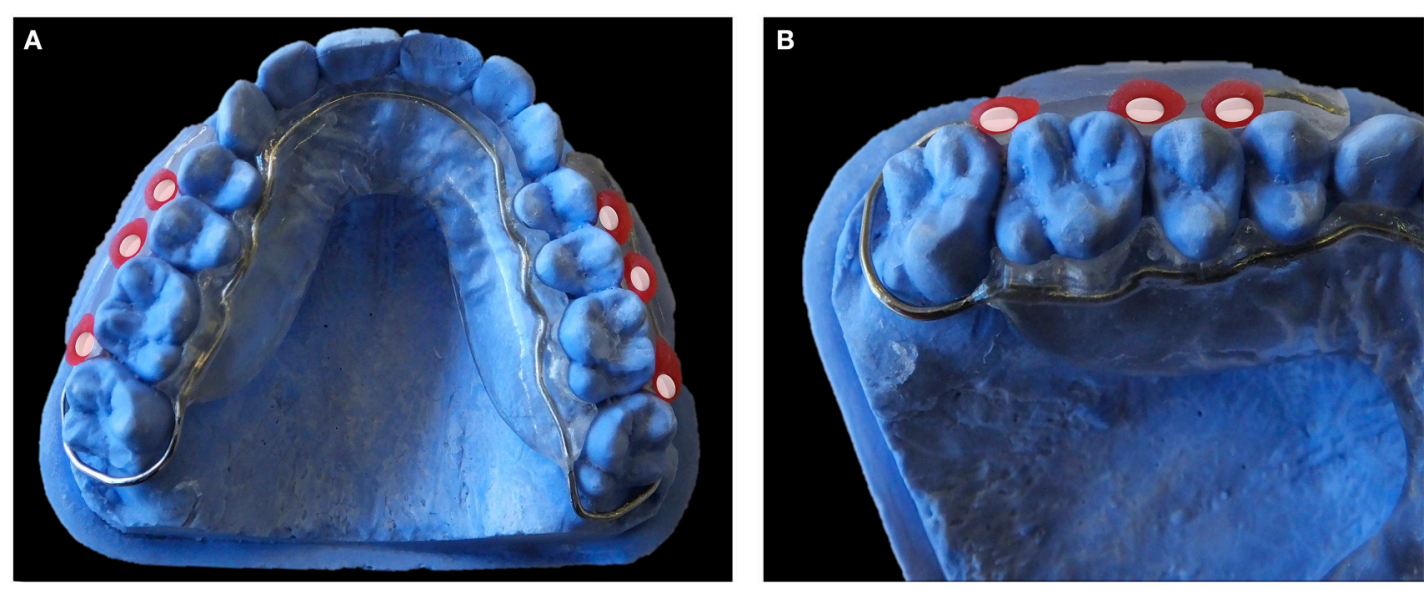

FIGURE 6 | Acrylic and metal device (AcMD). (A) Occlusal view. (B) Detail of the disk zone.

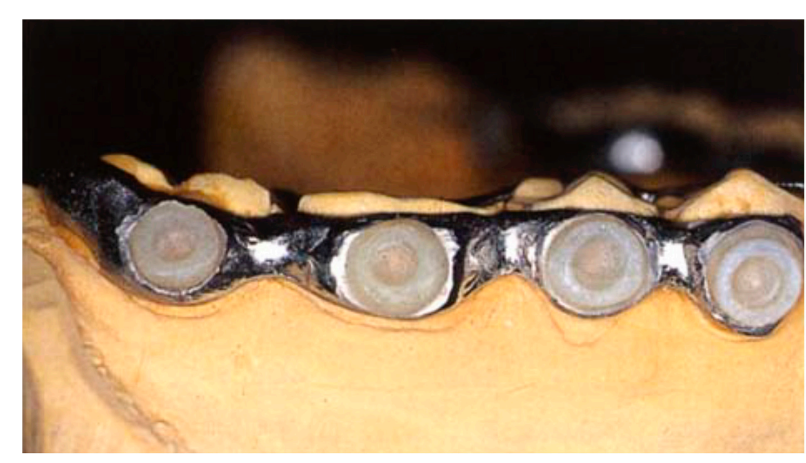

FIGURE 7 | Metal Device (MD). Image by Simion et al. (1997) in Clinical Oral Implants Research.

characteristics was standardized. The fact that the authors have also designed one of the apparatus reviewed could be a potential source of bias. When the list of items was devised the authors tried to abstract from their own design trying to be as "objective" as possible. The items were chosen, based on the authors' experience, for being of capital importance in an "ideal" device. Later, this checklist was modified after completely reading the selected articles in the present review.

The classification of the apparatus was designed prior to the start of the study and subsequently modified in order to clarify its presentation. As the group has previous experience in the field, a first classification based on the material of the device was established. After the data extraction, this classification was extended introducing the position of the substrates.

The review was focused mainly on buccal devices due to fact that both palatal and lingual devices have been less used in the existing literature. In the latter types of devices, the PL-Biofilm was always exposed to contact with the tongue; for this reason, the biofilm would be very disturbed. To prevent this from happening, authors devised protections such as a plastic mesh (in palatal devices) or an artificial gap between

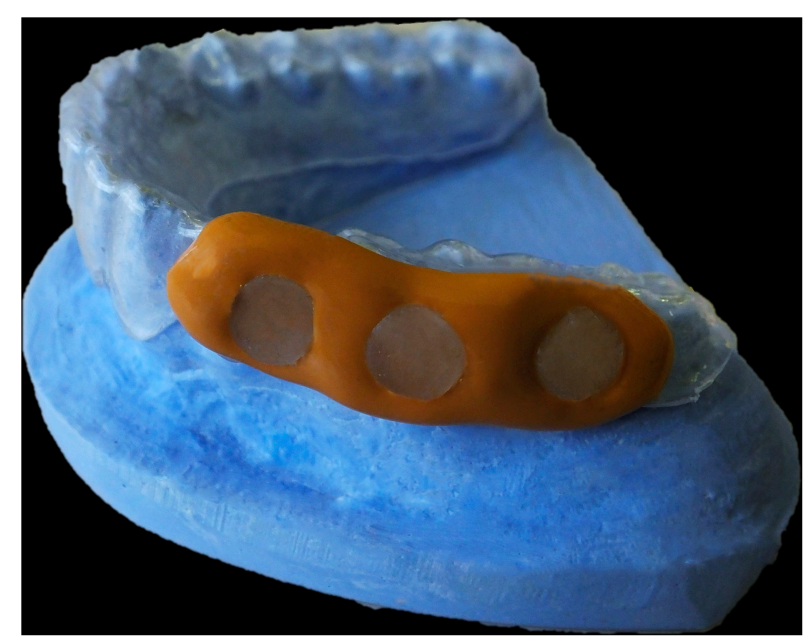

FIGURE 8 | Thermoplastic Device (TPD). Model of a thermoplastic and polysiloxane splint

the device and the lingual gingiva (in lingual devices). These protections would surely modify the growing environment of the PL-Biofilm, causing possibly, a lack of representativeness of the dental biofilm attached to the enamel surface. On the contrary, these devices permit the development of PL-Biofilm in absence of contact with the oral environment and poor renovation of saliva on its interior, allowing for the growing of biofilm covered with stagnated saliva. This particularity makes them to be useful for the replication of dental caries models. In any case, their use in PL-Biofilm studies is scarce (10 times less than buccal devices). A possible reason for this might be the big influence in phonetics that these devices have.

\section{Utility of the Devices Taking into Account the Microbiological Objective of the Study}

As previously stated, the intraoral devices for the development of PL-Biofilm have been faced to obtain very different results. 

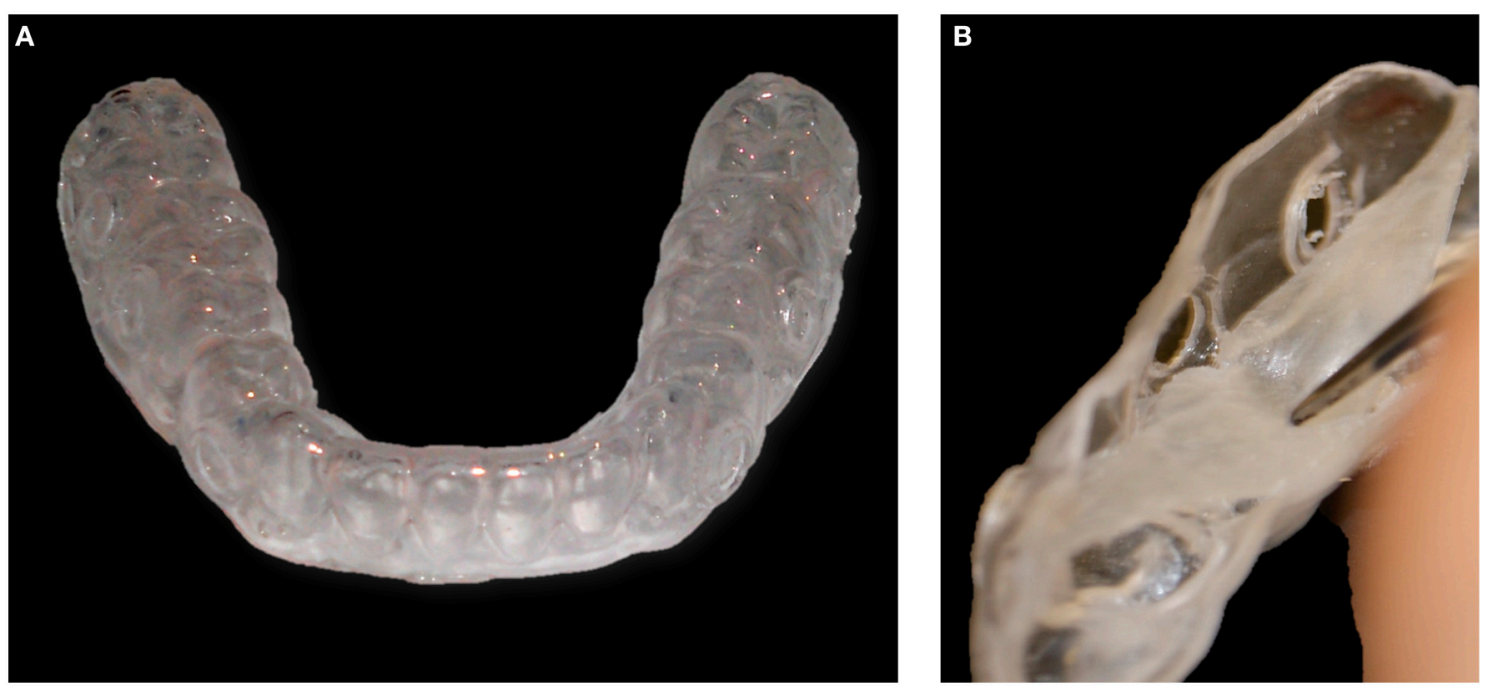

FIGURE 9 | Intraoral Device of Disk-holding Splints (IDODS). (A) Frontal view. (B) Detail of the pocket where the disks are placed.

These range from studying the covering grade of the biofilm, its thickness, bacterial viability or composition before and after applying several antimicrobial agents to the analysis of the effects that the PL-Biofilm itself may have onto a specific substrate. As stated in the material and methods section, the present review was only focused on the use of these devices in order to obtain a PL-Biofilm for a posterior microbiological evaluation. This evaluation has been done by CFUs, electronic microscopes (SEM or TEM), CLSM (after previous staining with dual live/dead fluorochromes or FISH and DAPI for bacterial identification and differentiation). All devices presented good properties in order to use one or another technique. In some cases the necessity of using one or another technique is going to be more related to the type of substrate that it is being used. For CFUs analysis, no troubles were found in any study in terms of collection of the sample, since the sample is harvested normally by vortexing the PL-Biofilm with the substrate (Leonhardt et al., 1995) or by collecting the PL-Biofilm with a cotton pellet directly from the substrate (Korytnicki et al., 2006). For CLSM analysis with previous staining, problems regarding substrates have been referred by some authors (Netuschil et al., 1998; Dige et al., 2007). The use of enamel, and sometimes hydroxyapatite has been related to episodes of autofluorescence of the substrate, increasing the difficulty of differentiation of the background and the sample itself (Netuschil et al., 1998). This can be corrected at the capture time with a specialized software. In any case, substrates that do not produce autofluorescence, such as glass, are preferred when possible, since the less the investigator has to "correct" the image the less biased the technique will be. In the case of using SEM, no troubles were found; with this technique, the sample is prepared for visualization within the substrate. Although no troubles were referred in any study using TEM, some problems may arise when doing the micro-cuts. This may be related to the excess of fragility of some materials. Hydroxyapatite disks due to their conglomerate structure, may shatter when the cut is done. Maybe for this reason, no study using TEM chose this material as a substrate.

\section{Characteristics of Buccal Devices}

Probably, in an effort to search the most similar substrate to the natural tooth surface, the most commonly used substrate has been the human enamel. Nowadays, other substrates such as titanium (Gosau et al., 2010; Giordano et al., 2011; Do Nascimento et al., 2013) or membranes (Simion et al., 1997; Zucchelli et al., 1998, 2000) are used more frequently in these devices for the study of peri-implantitis or the bacterial colonization in regenerative procedures.

The quantity of the substrates used depends on the design of the apparatus and the specific requirements for the aim of each of the studies. Depending on the latter, some devices are not eligible due to the impossibility of inclusion of enough samples (i.e., a study needing from more than four different samples from the same volunteer cannot be conducted using a $\mathrm{LiD)}$.

Scanning and Transmission Electronic Microscopy techniques, traditionally considered as the Gold standard for the visualization of the biofilm (Al-Ahmad et al., 2009), are not the most commonly used techniques in the selected studies. This is probably because of the necessity of altering the biofilm three-dimensional structure and the limitation of the analysis (Hannig et al., 2010). Because of this need of keeping the biofilm unaltered, fluorescence based microscopes, such as the epifluorescence and the CLSM, combined with FISH and DAPI for bacterial identification have been the preferred options. Another technique that has been widely used has been CFU counting, nowadays still considered the Gold standard in bacterial identification (Choudhry, 2016). Despite this, over the last decade, CFU counting has coexisted with other molecular techniques based on the identification of 
TABLE 2 | Main papers which used palatal and lingual devices for the study of in situ biofilm.

\begin{tabular}{lll}
\hline Palatal devices & & Lingual devices \\
\hline Benelli et al., 1993 & Gameiro et al., 2009 & Creanor et al., 1986 \\
Cury et al., 2001 & Lima et al., 2009 & Macpherson et al., 1990 \\
Hara et al., 2003 & Schwarz et al., 2009 & Macpherson et al., 1991 \\
Tenuta et al., 2003 & Sousa et al., 2009 & Jenkins et al., 1988 \\
Auschill et al., 2004* & Beyth et al., 2010 & Rasperini et al., 1998 \\
Paes Leme et al., 2004 & de Mazer Papa et al., 2010 & Sreenivasan et al., 2004 \\
Pecharki et al., 2005 & Brighenti et al., 2012 & Re et al., 2011 \\
Ribeiro et al., 2005 & Cochrane et al., 2012 & \\
Korytnicki et al., 2006 & Teixeira et al., 2012 & \\
Schwarz et al., 2006 & Melo et al., 2013 & \\
Arthur et al., 2007 & Pierro et al., 2013 & \\
Schwarz et al., 2007 & Bittar et al., 2014 & \\
Scotti et al., 2007* & Padovani et al., 2015 & \\
Paes Leme et al., 2008 & & \\
\hline
\end{tabular}

${ }^{*}$ Palatal and buccal devices were used.

the bacteria by their genome that have questioned the CFUs accuracy (Benítez-Páez et al., 2013), since more than 50\% of the bacteria present in the oral cavity are not culturable (Aas et al., 2005).

A wide range of biofilm maturation has been found in this review. Of course, this is a characteristic which is directly related to the aim of the studies. As the devices may be used for long periods of time, the apparatus should be properly designed, not affecting the volunteer's comfort. In the present review, the authors have taken into account that dental biofilm in terms of maturation may be generally considered after $4 \mathrm{~h}$. Before this time, there may possibly exist bacteria adhered to the acquired pellicle. In fact, Hannig et al. (2007a) found bacteria adhered to the acquired pellicle at $3 \mathrm{~min}$; in any case, they were only first colonizers and cannot be considered as a bacterial aggregate which will define a biofilm itself. In the present systematic review, papers analyzing biofilm after $4 \mathrm{~h}$ have been considered although in their measures have included any measure before this interval. Nevertheless, we have found authors that analyzed acquired pellicel at $2 \mathrm{~h}$ and other authors that analyzed CFUs since the very first $10 \mathrm{~min}$ (Leonhardt et al., 1995), or applied FISH tecniques at 30 min (Al-Ahmad et al., 2013).

The pre-treatment of the teeth with etching, bonding/debonding procedures and the posterior composite removal could damage enamel. This could result in the production of whitelesions or demineralizations similar to those caused by fixed orthodontia (Artun and Thylstrup, 1986). As the general rule should be to harm the volunteer's integrity as little as possible, devices retained without being adhered to the tooth surface are preferred.

Accidental loss of samples is a problem that has been found in those apparatus ( $\mathrm{LiD}$ ) where disks are attached to the tooth surface. The same situation has been reported in the AcD, AcMD, and $\mathrm{MD}$ groups, where specimens are glued or fixed to the device with wax. TPD and IDODS have specific zones where the disks are perfectly retained. Accidentally dropping samples

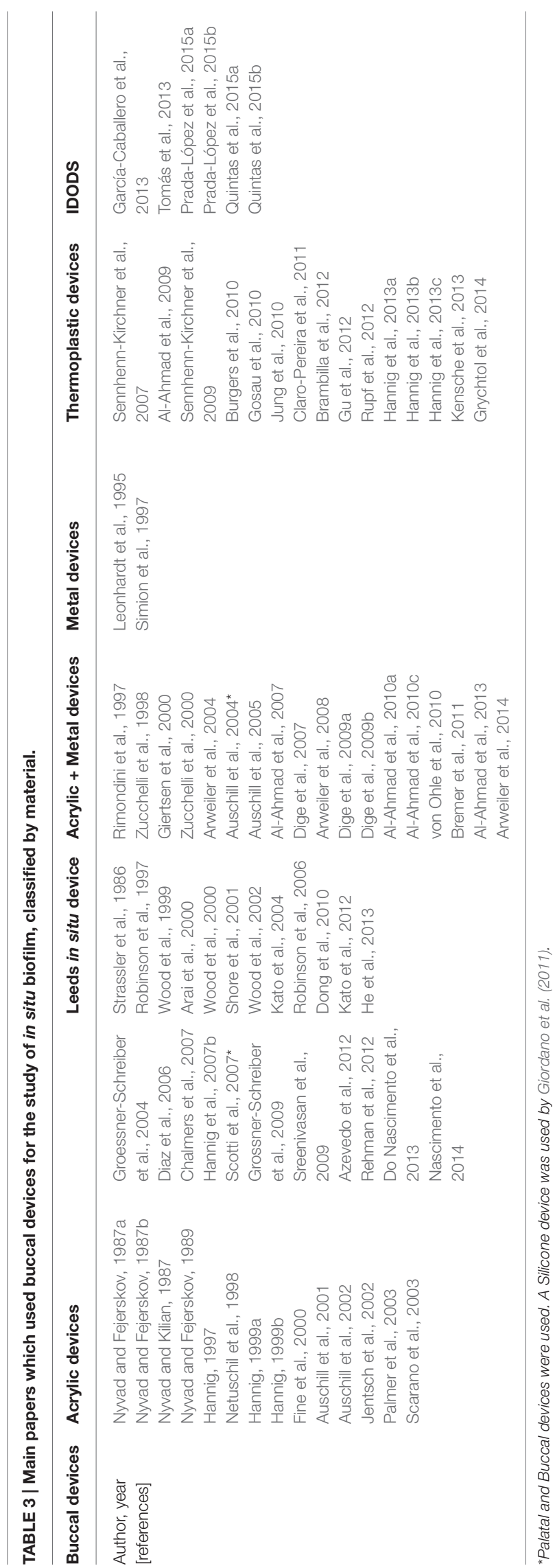


TABLE 4 | Evaluation of the characteristics of buccal devices, as well as the total number of advantages and limitations.

\begin{tabular}{|c|c|c|c|c|c|c|c|}
\hline Devices & $\begin{array}{l}\text { Acrylic } \\
\text { devices }\end{array}$ & $\begin{array}{l}\text { Leeds in situ } \\
\text { device }\end{array}$ & $\begin{array}{l}\text { Acrylic + } \\
\text { Metal devices }\end{array}$ & Metal devices & Thermo. devices & IDODS & $\begin{array}{c}\text { TOTAL advantages/ } \\
\text { limitations }\end{array}$ \\
\hline \multicolumn{8}{|l|}{ CHARACTERISTICS } \\
\hline Teeth pre-treatment is not necessary & $\checkmark$ & $x$ & $\checkmark$ & $\checkmark$ & $\checkmark$ & $\checkmark$ & $5 / 1$ \\
\hline Specific teeth are not necessary & $\checkmark$ & $x$ & $\checkmark$ & $\checkmark$ & $\checkmark$ & $\checkmark$ & $5 / 1$ \\
\hline No accidental unsticking & $x$ & $x$ & $x$ & $x$ & $\checkmark$ & $\checkmark$ & $2 / 4$ \\
\hline Allows eating & $x$ & $\checkmark$ & $\checkmark$ & $\checkmark$ & $x$ & $x$ & $3 / 3$ \\
\hline Easy withdrawal by the volunteer & $\checkmark$ & $x$ & $\checkmark$ & $\checkmark$ & $\checkmark$ & $\checkmark$ & $5 / 1$ \\
\hline Easy withdrawal of the sample & $x$ & $x$ & $x$ & $x$ & $\checkmark$ & $\checkmark$ & $2 / 4$ \\
\hline No contact with cheek /tongue & $x$ & $x$ & $\checkmark$ & $\checkmark$ & $\checkmark$ & $\checkmark$ & $4 / 2$ \\
\hline Allows salivary flow through the splint & $x$ & $x$ & $x$ & $x$ & $x$ & $\checkmark$ & $1 / 5$ \\
\hline Allows good oral hygiene & $\checkmark$ & $x$ & $\checkmark$ & $\checkmark$ & $\checkmark$ & $\checkmark$ & $5 / 1$ \\
\hline Good esthetic & $x$ & $\checkmark$ & $x$ & $x$ & $\checkmark$ & $\checkmark$ & $3 / 3$ \\
\hline Little bulky & $x$ & $\checkmark$ & $\checkmark$ & $\checkmark$ & $\checkmark$ & $\checkmark$ & $5 / 1$ \\
\hline Adaptable on the 1st appointment & $x$ & $\checkmark$ & $x$ & $x$ & $x$ & $x$ & $1 / 5$ \\
\hline Easy placement at 1 st time & $\checkmark$ & $x$ & $\checkmark$ & $\checkmark$ & $\checkmark$ & $\checkmark$ & $5 / 1$ \\
\hline Price of the material & + & ++ & ++++ & +++++ & +++ & ++++ & \\
\hline TOTAL advantages/limitations & $5 / 8$ & $4 / 9$ & $8 / 5$ & $8 / 5$ & $10 / 3$ & $11 / 2$ & \\
\hline
\end{tabular}

$\checkmark=$ The device meets this characteristic.

$\boldsymbol{x}=$ The device does not meet this characteristic.

$+=$ Relative cost of the manufacturing.

is an important issue, not only for the study, which will lose a specimen, but for medical reasons, due to the potential bronchial aspiration of the disk, which would cause an emergency situation.

A common limitation that applies to most devices is the inability to eat with the apparatus while wearing it. This characteristic would allow the analysis of the biofilm growing in the presence of nutrients coming directly from food. Although, the withdrawal period during meals is brief $(15-30 \mathrm{~min})$ and the devices are generally kept in a humid environment, this action implies that the biofilm is not exposed to nutrients or the self-cleansing action of chewing.

The impossibility to remove the LiD by the volunteer hinders the oral hygiene level in the vicinity of the device. Other devices can be removed by the volunteer in order to perform their oral hygiene measures normally (according to the protocol of the study). The ability to brush the teeth makes the use of these devices suitable for volunteers with specific oral diseases, who need to maintain good oral hygiene, such as patients with periodontitis. The study of this biofilm in situ could be the ideal method to achieve better knowledge and control of the disease (Marsh, 2005).

The withdrawal of the sample from the LiD by the investigator with a forceps or bracket-removing pliers might disturb the in situ biofilm. The same situation is reported when the investigator withdraws the disk from an $\mathrm{AcD}$ or AcMD. The design of both TPD and IDODS permit an easy removal of the specimen from the device with tweezers, without disturbing the biofilm.

Another important factor which could disturb the biofilm is contact with the cheeks and tongue during the period when the device is inside the oral cavity. In most apparatus, this issue has been solved with the design of a specific framework that protects the substrate. In the case of the AcMD, the disk is located facing the teeth, avoiding contact with the cheeks. In this specific situation, the growing conditions of the PL-Biofilm are completely different from the real situation given in the buccal teeth surface.

During the oral biofilm formation, the flow of saliva supplies the disk with nutrients (Bowden and Li, 1997). For this reason, if the device encounters a correct salivary flow, the biofilm on the disk will have sufficient nutrients, even though it is contained within the splint. The IDODS was the only device that enabled this salivary flow with a perforation located under every specimen. This salivary flow would not be desirable when studying certain types of biofilms found in places with difficult access, where this flow is limited or even absent (in caries models, for example). To the analysis of that biofilm, it would be necessary to design another type of device which does not permit any salivary flow through the specimen. In the present review, only some palatal and lingual devices (Cury et al., 2001; Tenuta et al., 2003) and one modification of the LiD (He et al., 2013), could be used for this purpose.

Another important criterion that should be taken into account when designing a biofilm device is its effect on the volunteer's comfort. The normal life of subjects is altered by all devices, especially by the bulk of the device and the type of material used, both esthetically and phonetically. If the volunteer's comfort is not affected or is affected as little as possible by the wearing of the device, the volunteer will better fulfill the protocol. If the device is uncomfortable or not esthetic, the volunteers might change their diet or reduce the duration for which the device is placed inside the oral cavity. Every change in their normal life will produce a bias in the growing biofilm. Despite the importance of 
these parameters, only one study which discussed the volunteer's experience with the device was found after this review (PradaLópez et al., 2015b). On the other hand, some papers have registered dropouts by the volunteers during the experiment, because of discomfort (Brambilla et al., 2012) or unclear reasons (Arweiler et al., 2014).

\section{Device Modifications}

Finally, it is important to highlight that some authors made small variations from the prototype. For instance, in 2012, Gu et al. (2012) added an orthodontic wire to the TPD with the aim of making it more resistant. In the same way, and in order to improve the LiD design, He et al. (2013) used an additional metal sheet to protect the biofilm from contact with the cheek (Figures 10A,B); eventually, this modification meant that the biofilm grew between two metals, without taking into account the electric covalent flows produced between two face-to-face metal sheets, which would undoubtedly affect the development of the biofilm.

\section{Ideal Model for PL-Biofilm Development}

After this deep review of the existent literature, the authors would like to show their own perspective of the "ideal" in situ model for PL-Biofilm development. In the authors' opinion, the ideal device should meet at least all the previously stated ideal characteristics (Table 1). After their analysis, it seems clear that it should be made of a transparent material (polyethylene, silicone...) for esthetic reasons. It should not be glued on the surface of the teeth in order not to damage them in any extent. In addition, the device should be designed for disk accommodation without gluing; this will avoid accidental loss of specimens. Moreover, the device should permit removal from the oral cavity to allow the volunteer to perform their daily oral hygiene measures. Furthermore, it would be desirable that the apparatus was designed to facilitate the salivary flow through it, simulating the interproximal spaces. All these, and other characteristics, are only fulfilled by the IDODS, being the one that is closest to the "ideal" model. On the other hand, there are other aspects that should be improved in its design: the impossibility to eat with it and the need of more than one appointment for its adaptation. Its design should evolve into a model which does not cover the occlusal faces of the teeth (permitting eating while wearing it). The vestibular band of the IDODS could be used instead of all apparatus. This would allow that the occlusal surfaces of the teeth would not be covered anymore. Other ways of retention, apart from self-retention of the teeth or gluing would be possible. Using orthodontic wires or rubbers may help with this. At the same time, this would permit device removal from the mouth by the volunteer for oral hygiene measures, but also the possibility to eat with them to get closer to the clinical reality of the tooth surfaces. This modification could also help in their adaptability due to the fact that only the vestibular part of the hemi-arch would be used. Consequently, it might allow the design of a standard vestibular part of the apparatus (maybe three different sizes) avoiding the need of more than one appointment for its adaptation.

\section{Future Investigations}

The majority of the published papers have not described the device or the manufacturing methodology properly. In these cases, reproduction of any device would be more difficult, and standardization would be impossible. Consequently, the potential to compare results between studies or to apply the same methodology would be a utopian situation. For this reason, a specific description would be very useful when any groups subsequently design new devices, as previously included by some authors (Robinson et al., 1997; Sreenivasan et al., 2009; Tomás et al., 2013; Prada-López et al., 2015b; Quintas et al., 2015b).

In addition, no papers could be identified which have compared the characteristics of the device-formed-biofilm positioned at buccal (PL-Biofilm) with the tooth-formed-biofilm (dental plaque). From the authors' point of view, the quality or the relevance of the PL-Biofilm should be the primary issue of every study on oral biofilm. When using a device in order to assess ex vivo the biofilm formed in situ, the first question that a researcher should pose would be if the biofilm formed in the artificial substrate is representative of that characteristic to be studied (biofilm in a caries lesion, biofilm in the interproximal area, biofilm in the vestibular area...). Unfortunately, not a
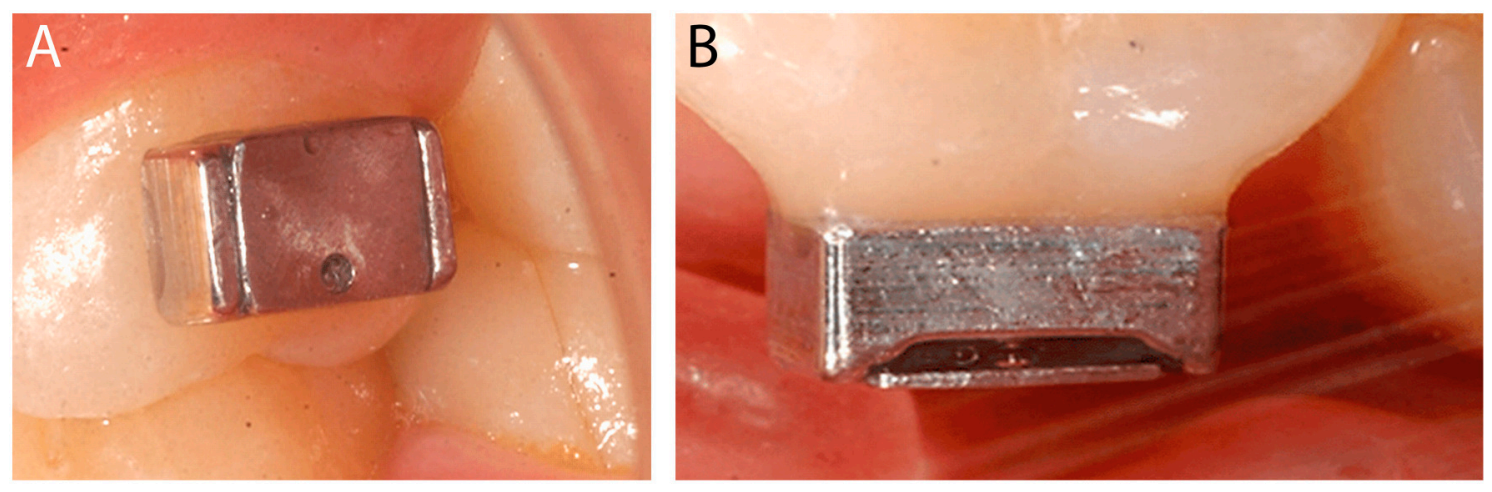

FIGURE 10 | Modification of the Leeds in situ device (by He et al., 2013 in Plos One). (A) Intraoral buccal view. (B) Detail of the gap between the two metal slides where the biofilm grows. 
single study has proved this until the moment. To overcome this limitation, our group has designed a study for testing the bacterial viability and composition of the PL-Biofilm, comparing at the same time with the contralateral teeth in a split-mouth design. This will permit to evaluate and validate the biofilm formed on the substrates carried in the IDODS compared to that naturally formed in the surface of the teeth (unpublished data). This comparison would confirm the correct validation of the device and provide more evidence of its applicability to the study of the oral biofilm in situ. Previously, following this idea, Creanor et al. (1986) analyzed the CFUs on a lingual device and compared them to those found in natural dental surface, but only in one volunteer. They found that the microbial composition of their PL-Biofilm was relatively consistent compared the natural plaque, although the latter showed more variation.

In the present review, only one study which used selfperception questionnaires was identified. Prada-López et al. (2015b) used a Likert-type questionnaire to evaluate the influence of the device in the esthetics, hygiene, comfort and complication of withdrawal. The questionnaire showed really acceptable results of the influence of the IDODS on the volunteer's life. For further investigations, a questionnaire which measures the influence of the device on the normal daily life of the volunteer would be useful, as it would provide a more accurate vision of the volunteer's comfort whilst wearing these devices.

\section{CONCLUSION}

Buccal devices were the most commonly used for the study of in situ biofilm. The majority of buccal devices seemed to slightly affect the volunteer's comfort, the IDODS being the closest to the "ideal" model. However, there are other aspects that should be

\section{REFERENCES}

Aas, J. A., Paster, B. J., Stokes, L. N., Olsen, I., and Dewhirst, F. E. (2005). Defining the normal bacterial flora of the oral cavity. J. Clin. Microbiol. 43, 5721-5732. doi: 10.1128/JCM.43.11.5721-5732.2005

Ahrens, G. (1976). Effect of fluoride tablets on uptake and loss of fluoride in superficial enamel in vivo. Caries Res. 10, 85-95. doi: 10.1159/000260192

Al-Ahmad, A., Follo, M., Selzer, A. C., Hellwig, E., Hannig, M., and Hannig, C. (2009). Bacterial colonization of enamel in situ investigated using fluorescence in situ hybridization. J. Med. Microbiol. 58, 1359-1366. doi: 10.1099/jmm.0.011213-0

Al-Ahmad, A., Maier, J., Follo, M., Spitzmuller, B., Wittmer, A., Hellwig, E., et al. (2010a). Food-borne enterococci integrate into oral biofilm: an in vivo study. J. Endod. 36, 1812-1819. doi: 10.1016/j.joen.2010.08.011

Al-Ahmad, A., Roth, D., Wolkewitz, M., Wiedmann-Al-Ahmad, M., Follo, M., Ratka-Kruger, P., et al. (2010b). Change in diet and oral hygiene over an 8-week period: effects on oral health and oral biofilm. Clin. Oral Investig. 14, 391-396. doi: 10.1007/s00784-009-0318-9

Al-Ahmad, A., Wiedmann-Al-Ahmad, M., Fackler, A., Follo, M., Hellwig, E., Bachle, M., et al. (2013). In vivo study of the initial bacterial adhesion on different implant materials. Arch. Oral Biol. 58, 1139-1147. doi: 10.1016/j.archoralbio.2013.04.011

Al-Ahmad, A., Wiedmann-Al-Ahmad, M., Faust, J., Bachle, M., Follo, M., Wolkewitz, M., et al. (2010c). Biofilm formation and composition on different improved in its design: the impossibility to eat with it and the need of more than one appointment for its adaptation.

Papers should include more information about manufacturing their devices. Therefore, any new device must consider the limitations of the previous ones, paying particular attention to the needs of the volunteer and the biofilm formation. In addition, all of the devices must test the volunteer's experience and the microbiological differences between device-formed biofilm and tooth-formed biofilm and studies should include a feedback exercise.

\section{AUTHOR CONTRIBUTIONS}

IP, VQ Conception and design of the review, revising of the literature, acquisition, and analysis of data and drafting the article. CV Making different devices for obtaining figures and revising of the literature. DS, IT Conception and design of the review, revising of the literature and manuscript and final approval.

\section{FUNDING}

This work was supported by project EM2014/025 from Regional Ministry of Culture, Education and University (regional government of Galicia, Spain), which is integrated in Regional Plan of Research, Innovation and Development 2011-2015. The funders had no role in study design, data collection and analysis, decision to publish, or preparation of the manuscript.

\section{SUPPLEMENTARY MATERIAL}

The Supplementary Material for this article can be found online at: http://journal.frontiersin.org/article/10.3389/fmicb. 2016.01055

implant materials in vivo. J. Biomed. Mater. Res. B Appl. Biomater. 95, 101-109. doi: 10.1002/jbm.b.31688

Al-Ahmad, A., Wunder, A., Auschill, T. M., Follo, M., Braun, G., Hellwig, E., et al. (2007). The in vivo dynamics of Streptococcus spp., Actinomyces naeslundii, Fusobacterium nucleatum and Veillonella spp. in dental plaque biofilm as analysed by five-colour multiplex fluorescence in situ hybridization. J. Med. Microbiol. 56, 681-687. doi: 10.1099/jmm.0.47094-0

Arai, K., Kato, K., Nakagaki, H., Toyama, A., Nagai, N., Noguchi, T., et al. (2000). Fluoride profiles in dental plaque in vivo formed on fluoride pre-treated human enamel. Caries Res. 34, 254-259. doi: 10.1159/000016599

Arthur, R. A., Tabchoury, C. P., Mattos-Graner, R. O., Del Bel Cury, A. A., PaesLeme, A. F., Vale, G. C., et al. (2007). Genotypic diversity of S. mutans in dental biofilm formed in situ under sugar stress exposure. Braz. Dent. J. 18, 185-191. doi: 10.1590/S0103-64402007000300002

Artun, J., and Thylstrup, A. (1986). Clinical and scanning electron microscopic study of surface changes of incipient caries lesions after debonding. Scand. J. Dent. Res. 94, 193-201.

Arweiler, N. B., Boehnke, N., Sculean, A., Hellwig, E., and Auschill, T. M. (2006) Differences in efficacy of two commercial $0.2 \%$ chlorhexidine mouthrinse solutions: a 4-day plaque re-growth study. J. Clin. Periodontol. 33, 334-339. doi: 10.1111/j.1600-051X.2006.00917.x

Arweiler, N. B., Hellwig, E., Sculean, A., Hein, N., and Auschill, T. M. (2004). Individual vitality pattern of in situ dental biofilms at different locations in the oral cavity. Caries Res. 38, 442-447. doi: 10.1159/000079625 
Arweiler, N. B., Lenz, R., Sculean, A., Al-Ahmad, A., Hellwig, E., and Auschill, T. M. (2008). Effect of food preservatives on in situ biofilm formation. Clin. Oral Investig. 12, 203-208. doi: 10.1007/s00784-008-0188-6

Arweiler, N. B., Netuschil, L., Beier, D., Grunert, S., Heumann, C., Altenburger, M. J., et al. (2014). Action of food preservatives on 14-days dental biofilm formation, biofilm vitality and biofilm-derived enamel demineralisation in situ. Clin. Oral Investig. 18, 829-838. doi: 10.1007/s00784-013-1053-9

Auschill, T. M., Arweiler, N. B., Brecx, M., Reich, E., Sculean, A., and Netuschil, L. (2002). The effect of dental restorative materials on dental biofilm. Eur. J. Oral Sci. 110, 48-53. doi: 10.1046/j.0909-8836.2001.101160.x

Auschill, T. M., Arweiler, N. B., Netuschil, L., Brecx, M., Reich, E., and Sculean, A. (2001). Spatial distribution of vital and dead microorganisms in dental biofilms. Arch. Oral Biol. 46, 471-476. doi: 10.1016/S0003-9969(00)00136-9

Auschill, T. M., Hein, N., Hellwig, E., Follo, M., Sculean, A., and Arweiler, N. B. (2005). Effect of two antimicrobial agents on early in situ biofilm formation. J. Clin. Periodontol. 32, 147-152. doi: 10.1111/j.1600-051X.2005.00650.x

Auschill, T. M., Hellwig, E., Sculean, A., Hein, N., and Arweiler, N. B. (2004). Impact of the intraoral location on the rate of biofilm growth. Clin. Oral Investig. 8, 97-101. doi: 10.1007/s00784-004-0255-6

Azevedo, S. M., Kantorski, K. Z., Valandro, L. F., Bottino, M. A., and Pavanelli, C. A. (2012). Effect of brushing with conventional versus whitening dentifrices on surface roughness and biofilm formation of dental ceramics. Gen. Dent. 60, e123-e130.

Benelli, E. M., Serra, M. C., Rodrigues, A. L. Jr., and Cury, J. A. (1993). In situ anticariogenic potential of glass ionomer cement. Caries Res. 27, 280-284. doi: 10.1159/000261551

Benítez-Páez, A., Álvarez, M., Belda-Ferre, P., Rubido, S., Mira, A., and Tomás, I. (2013). Detection of transient bacteraemia following dental extractions by $16 \mathrm{~S}$ rDNA pyrosequencing: a pilot study. PLOS ONE 8:e57782. doi: 10.1371/journal.pone.0057782

Beyth, N., Yudovin-Farber, I., Perez-Davidi, M., Domb, A. J., and Weiss, E. I. (2010). Polyethyleneimine nanoparticles incorporated into resin composite cause cell death and trigger biofilm stress in vivo. Proc. Natl. Acad. Sci. U.S.A. 107, 22038-22043. doi: 10.1073/pnas.1010341107

Biofilm Club, M., and Gilbert, P. (2007). Biofilms: Coming of Age: Contributions Made at the Eighth Meeting of the Biofilm Club held at Gregynog Hall, Powys 5th-7th September 2007. Manchester: Biofilm Club.

Bittar, D. G., Pontes, L. R., Calvo, A. F., Novaes, T. F., Braga, M. M., Freitas, P. M., et al. (2014). Is the red fluorescence of dental plaque related to its cariogenicity? J. Biomed. Opt. 19:065004. doi: 10.1117/1.JBO.19.6.065004

Bowden, G. H., and Li, Y. H. (1997). Nutritional influences on biofilm development. Adv. Dent. Res. 11, 81-99. doi: 10.1177/08959374970110012101

Brambilla, E., Ionescu, A., Gagliani, M., Cochis, A., Arciola, C. R., and Rimondini, L. (2012). Biofilm formation on composite resins for dental restorations: an in situ study on the effect of chlorhexidine mouthrinses. Int. J. Artif. Organs 35, 792-799. doi: 10.5301/ijao.5000165

Bremer, F., Grade, S., Kohorst, P., and Stiesch, M. (2011). In vivo biofilm formation on different dental ceramics. Quintessence Int. 42, 565-574.

Brighenti, F. L., Gaetti-Jardim, E. Jr., Danelon, M., Evangelista, G. V., and Delbem, A. C. (2012). Effect of Psidium cattleianum leaf extract on enamel demineralisation and dental biofilm composition in situ. Arch. Oral Biol. 57, 1034-1040. doi: 10.1016/j.archoralbio.2012.02.009

Burgers, R., Gerlach, T., Hahnel, S., Schwarz, F., Handel, G., and Gosau, M. (2010). In vivo and in vitro biofilm formation on two different titanium implant surfaces. Clin. Oral Implants Res. 21, 156-164. doi: 10.1111/j.16000501.2009.01815.x

Chalmers, N. I., Palmer, R. J. Jr., Du-Thumm, L., Sullivan, R., Shi, W., and Kolenbrander, P. E. (2007). Use of quantum dot luminescent probes to achieve single-cell resolution of human oral bacteria in biofilms. Appl. Environ. Microbiol. 73, 630-636. doi: 10.1128/AEM.02164-06

Charles, C. H., Pan, P. C., Sturdivant, L., and Vincent, J. W. (2000). In vivo antimicrobial activity of an essential oil-containing mouthrinse on interproximal plaque bacteria. J. Clin. Dent. 11, 94-97.

Choudhry, P. (2016). High-throughput method for automated colony and cell counting by digital image analysis based on edge detection. PLoS ONE 11: e0148469. doi: 10.1371/journal.pone.0148469

Claro-Pereira, D., Sampaio-Maia, B., Ferreira, C., Rodrigues, A., Melo, L. F., and Vasconcelos, M. R. (2011). In situ evaluation of a new silorane-based composite resin's bioadhesion properties. Dent. Mater. 27, 1238-1245. doi: 10.1016/j.dental.2011.08.401

Cochrane, N. J., Shen, P., Byrne, S. J., Walker, G. D., Adams, G. G., Yuan, Y., et al. (2012). Remineralisation by chewing sugar-free gums in a randomised, controlled in situ trial including dietary intake and gauze to promote plaque formation. Caries Res. 46, 147-155. doi: 10.1159/000337240

Costerton, J. W., Stewart, P. S., and Greenberg, E. P. (1999). Bacterial biofilms: a common cause of persistent infections. Science 284, 1318-1322. doi: 10.1126/science.284.5418.1318

Creanor, S. L., Macfarlane, T. W., Mackenzie, D., Weetman, D. A., Strang, R., and Stephen, K. W. (1986). Microbiology and acid/anion profiles of enamel surface plaque from an in situ caries appliance. Caries Res. 20, 392-397. doi: $10.1159 / 000260964$

Cury, J. A., Francisco, S. B., Del Bel Cury, A. A., and Tabchoury, C. P. (2001). In situ study of sucrose exposure, mutans streptococci in dental plaque and dental caries. Braz. Dent. J. 12, 101-104.

Daneshmand, N., Jorgensen, M. G., Nowzari, H., Morrison, J. L., and Slots, J. (2002). Initial effect of controlled release chlorhexidine on subgingival microorganisms. J. Periodont. Res. 37, 375-379. doi: 10.1034/j.1600-0765.2002.01003.x

de Mazer Papa, A. M., Tabchoury, C. P., Del Bel Cury, A. A., Tenuta, L. M., Arthur, R. A., and Cury, J. A. (2010). Effect of milk and soy-based infant formulas on in situ demineralization of human primary enamel. Pediatr. Dent. 32, 35-40.

Diaz, P. I., Chalmers, N. I., Rickard, A. H., Kong, C., Milburn, C. L., Palmer, R. J. Jr., et al. (2006). Molecular characterization of subject-specific oral microflora during initial colonization of enamel. Appl. Environ. Microbiol. 72, 2837-2848. doi: 10.1128/AEM.72.4.2837-2848.2006

Dige, I., Nilsson, H., Kilian, M., and Nyvad, B. (2007). In situ identification of streptococci and other bacteria in initial dental biofilm by confocal laser scanning microscopy and fluorescence in situ hybridization. Eur. J. Oral Sci. 115, 459-467. doi: 10.1111/j.1600-0722.2007.00494.x

Dige, I., Nyengaard, J. R., Kilian, M., and Nyvad, B. (2009a). Application of stereological principles for quantification of bacteria in intact dental biofilms. Oral Microbiol. Immunol 24, 69-75. doi: 10.1111/j.1399-302X.2008.00482.x

Dige, I., Raarup, M. K., Nyengaard, J. R., Kilian, M., and Nyvad, B. (2009b). Actinomyces naeslundii in initial dental biofilm formation. Microbiology 155, 2116-2126. doi: 10.1099/mic.0.027706-0

Do Nascimento, C., Pita, M. S., Pedrazzi, V., de Albuquerque, R. F. Jr., and Ribeiro, R. F. (2013). In vivo evaluation of Candida spp. adhesion on titanium or zirconia abutment surfaces. Arch. Oral Biol. 58, 853-861. doi: 10.1016/j.archoralbio.2013.01.014

Dong, W. L., Zhou, Y. H., Li, C. Z., Liu, H., Shang, S. H., and Pan, B. Q. (2010). Establishment and application of an intact natural model of human dental plaque biofilm. Shanghai Kou Qiang Yi Xue 19, 196-201.

Fine, D. H., Furgang, D., Sinatra, K., Charles, C., McGuire, A., and Kumar, L. D. (2005). In vivo antimicrobial effectiveness of an essential oil-containing mouth rinse $12 \mathrm{~h}$ after a single use and 14 days' use. J. Clin. Periodontol. 32, 335-340. doi: 10.1111/j.1600-051x.2005.00674.x

Fine, D. H., Furgang, D., Steinberg, L. M., Olshan, A. M., Kohut, R. E., Coelho, J. F., et al. (2000). A model for clinical evaluation of anti-microbial effects of agents on plaque colonization. Am. J. Dent. 13, 153-158.

Gameiro, G. H., Nouer, D. F., Cenci, M. S., and Cury, J. A. (2009). Enamel demineralization with two forms of archwire ligation investigated using an in situ caries model-a pilot study. Eur. J. Orthod. 31, 542-546. doi: 10.1093/ejo/cjn119

García-Caballero, L., Quintas, V., Prada-López, I., Seoane, J., Donos, N., and Tomás, I. (2013). Chlorhexidine substantivity on salivary flora and plaque-like biofilm: an in situ model. PLoS ONE 8:e83522. doi: 10.1371/ journal.pone.0083522

Giertsen, E., Guggenheim, B., Thurnheer, T., and Gmur, R. (2000). Microbiological aspects of an in situ model to study effects of antimicrobial agents on dental plaque ecology. Eur. J. Oral Sci. 108, 403-411. doi: 10.1034/j.16000722.2000.108005403.x

Giordano, C., Saino, E., Rimondini, L., Pedeferri, M. P., Visai, L., Cigada, A., et al. (2011). Electrochemically induced anatase inhibits bacterial colonization on Titanium Grade 2 and Ti6Al4V alloy for dental and orthopedic devices. Colloids Surf B Biointerfaces 88, 648-655. doi: 10.1016/j.colsurfb.2011. 07.054 
Gosau, M., Hahnel, S., Schwarz, F., Gerlach, T., Reichert, T. E., and Burgers, R. (2010). Effect of six different peri-implantitis disinfection methods on in vivo human oral biofilm. Clin. Oral Implants Res. 21, 866-872. doi: 10.1111/j.16000501.2009.01908.x

Groessner-Schreiber, B., Hannig, M., Duck, A., Griepentrog, M., and Wenderoth, D. F. (2004). Do different implant surfaces exposed in the oral cavity of humans show different biofilm compositions and activities?. Eur. J. Oral Sci. 112, 516-522. doi: 10.1111/j.1600-0722.2004.00171.x

Grossner-Schreiber, B., Teichmann, J., Hannig, M., Dorfer, C., Wenderoth, D. F., and Ott, S. J. (2009). Modified implant surfaces show different biofilm compositions under in vivo conditions. Clin. Oral Implants Res. 20, 817-826. doi: 10.1111/j.1600-0501.2009.01729.x

Grychtol, S., Basche, S., Hannig, M., and Hannig, C. (2014). Effect of CPP/ACP on initial bioadhesion to enamel and dentin in situ. Sci. World J. 2014:512682. doi: $10.1155 / 2014 / 512682$

Gu, H., Fan, D., Gao, J., Zou, W., Peng, Z., Zhao, Z., et al. (2012). Effect of $\mathrm{ZnCl} 2$ on plaque growth and biofilm vitality. Arch. Oral Biol. 57, 369-375. doi: 10.1016/j.archoralbio.2011.10.001

Hannig, C., Basche, S., Burghardt, T., Al-Ahmad, A., and Hannig, M. (2013a). Influence of a mouthwash containing hydroxyapatite microclusters on bacterial adherence in situ. Clin. Oral Investig. 17, 805-814. doi: 10.1007/s00784-0120781-6

Hannig, C., Follo, M., Hellwig, E., and Al-Ahmad, A. (2010). Visualization of adherent micro-organisms using different techniques. J. Med. Microbiol. 59, 1-7. doi: 10.1099/jmm.0.015420-0

Hannig, C., Gaeding, A., Basche, S., Richter, G., Helbig, R., and Hannig, M. (2013b). Effect of conventional mouthrinses on initial bioadhesion to enamel and dentin in situ. Caries Res. 47, 150-161. doi: 10.1159/000345083

Hannig, C., and Hannig, M. (2009). The oral cavity-a key system to understand substratum-dependent bioadhesion on solid surfaces in man. Clin. Oral Investig. 13, 123-139. doi: 10.1007/s00784-008-0243-3

Hannig, C., Hannig, M., Rehmer, O., Braun, G., Hellwig, E., and Al-Ahmad, A. (2007a). Fluorescence microscopic visualization and quantification of initial bacterial colonization on enamel in situ. Arch. Oral Biol. 52, 1048-1056. doi: 10.1016/j.archoralbio.2007.05.006

Hannig, C., Kirsch, J., Al-Ahmad, A., Kensche, A., Hannig, M., and Kummerer, K. (2013c). Do edible oils reduce bacterial colonization of enamel in situ? Clin. Oral Investig. 17, 649-658. doi: 10.1007/s00784-012-0734-0

Hannig, M. (1997). Transmission electron microscopic study of in vivo pellicle formation on dental restorative materials. Eur. J. Oral Sci. 105, 422-433. doi: 10.1111/j.1600-0722.1997.tb02139.x

Hannig, M. (1999a). Transmission electron microscopy of early plaque formation on dental materials in vivo. Eur. J. Oral Sci. 107, 55-64.

Hannig, M. (1999b). Ultrastructural investigation of pellicle morphogenesis at two different intraoral sites during a 24-h period. Clin. Oral Investig. 3, 88-95.

Hannig, M., Kriener, L., Hoth Hannig, W., Becker Willinger, C., and Schmidt, H. (2007b). Influence of nanocomposite surface coating on biofilm formation in situ. J. Nanosci. Nanotechnol. 7, 4642-4648. doi: 10.1166/jnn.2007.005

Hara, A. T., Queiroz, C. S., Paes-Leme, A. F., Serra, M. C., and Cury, J. A. (2003), Caries progression and inhibition in human and bovine root dentine in situ. Caries Res. 37, 339-344. doi: 10.1159/000072165

He, Y., Peterson, B. W., Jongsma, M. A., Ren, Y., Sharma, P. K., Busscher, H. J., et al. (2013). Stress relaxation analysis facilitates a quantitative approach towards antimicrobial penetration into biofilms. PLOS ONE 8:e63750. doi: 10.1371/journal.pone.0063750

Jefferson, K. K., and Cerca, N. (2006). Bacterial-bacterial cell interactions in biofilms: detection of polysaccharide intercellular adhesins by blotting and confocal microscopy. Methods Mol. Biol. 341, 119-126. doi: 10.1385/1-59745113-4:119

Jenkins, S., Addy, M., and Wade, W. (1988). The mechanism of action of chlorhexidine. A study of plaque growth on enamel inserts in vivo. J. Clin. Periodontol. 15, 415-424. doi: 10.1111/j.1600-051X.1988.tb01595.x

Jentsch, H., Hombach, A., Beetke, E., and Jonas, L. (2002). Quantitative transmission electron microscopic study of dental plaque-an in vivo study with different mouthrinses. Ultrastruct. Pathol. 26, 309-313. doi: 10.1080/01913120290104584

Jongsma, M. A., van de Lagemaat, M., Busscher, H. J., Geertsema-Doornbusch, G. I., Atema-Smit, J., van der Mei, H. C., et al. (2015). Synergy of brushing mode and antibacterial use on in vivo biofilm formation. J. Dent. 43, 1580-1586. doi: 10.1016/j.jdent.2015.08.001

Jung, D. J., Al-Ahmad, A., Follo, M., Spitzmuller, B., Hoth-Hannig, W., Hannig, M., et al. (2010). Visualization of initial bacterial colonization on dentine and enamel in situ. J. Microbiol. Methods 81, 166-174. doi: 10.1016/ j.mimet.2010.03.002

Kato, K., Sato, T., Takahashi, N., Fukui, K., Yamamoto, K., and Nakagaki, H. (2004). A method for mapping the distribution pattern of cariogenic streptococci within dental plaque in vivo. Caries Res. 38, 448-453. doi: 10.1159/000079626

Kato, K., Tamura, K., and Nakagaki, H. (2012). Quantitative evaluation of the oral biofilm-removing capacity of a dental water jet using an electron-probe microanalyzer. Arch. Oral Biol. 57, 30-35. doi: 10.1016/ j.archoralbio.2011.08.006

Kensche, A., Basche, S., Bowen, W. H., Hannig, M., and Hannig, C. (2013). Fluorescence microscopic visualization of non cellular components during initial bioadhesion in situ. Arch. Oral Biol. 58, 1271-1281. doi: 10.1016/j.archoralbio.2013.07.006

Kolenbrander, P. E., Palmer, R. J. Jr., Rickard, A. H., Jakubovics, N. S., Chalmers, N. I., and Diaz, P. I. (2006). Bacterial interactions and successions during plaque development. Periodontol. 2000 42, 47-79. doi: 10.1111/j.16000757.2006.00187.x

Konig, J., Storcks, V., Kocher, T., Bossmann, K., and Plagmann, H. C. (2002). Antiplaque effect of tempered $0.2 \%$ chlorhexidine rinse: an in vivo study. J. Clin. Periodontol. 29, 207-210. doi: 10.1034/j.1600-051x.2002.290304.x

Korytnicki, D., Mayer, M. P., Daronch, M., Singer Jda, M., and Grande, R. H. (2006). Effects of Nd:YAG laser on enamel microhardness and dental plaque composition: an in situ study. Photomed. Laser Surg. 24, 59-63. doi: 10.1089/pho.2006.24.59

Koulourides, T., Bodden, R., Keller, S., Manson-Hing, L., Lastra, J., and Housch, T. (1976). Cariogenicity of nine sugars tested with an intraoral device in man. Caries Res. 10, 427-441. doi: 10.1159/000260235

Leonhardt, A., Olsson, J., and Dahlen, G. (1995). Bacterial colonization on titanium, hydroxyapatite, and amalgam surfaces in vivo. J. Dent. Res. 74, 1607-1612. doi: 10.1177/00220345950740091701

Li, X., Kolltveit, K. M., Tronstad, L., and Olsen, I. (2000). Systemic diseases caused by oral infection. Clin. Microbiol. Rev. 13, 547-558. doi: 10.1128/CMR.13.4.547558.2000

Liberati, A., Altman, D. G., Tetzlaff, J., Mulrow, C., Gotzsche, P. C., Ioannidis, J. P., et al. (2009). The PRISMA statement for reporting systematic reviews and meta-analyses of studies that evaluate health care interventions: explanation and elaboration. J. Clin. Epidemiol. 62, e1-e34. doi: 10.1136/bmj.b2700

Lima, J. P., Sampaio de Melo, M. A., Borges, F. M., Teixeira, A. H., Steiner-Oliveira, C., Nobre Dos Santos, M., et al. (2009). Evaluation of the antimicrobial effect of photodynamic antimicrobial therapy in an in situ model of dentine caries. Eur. J. Oral Sci. 117, 568-574. doi: 10.1111/j.1600-0722.2009.00662.x

Loivukene, K., Pahkla, E. R., Koppel, T., Saag, M., and Naaber, P. (2005). The microbiological status of patients with periodontitis in southern Estonia after non-surgical periodontal therapy. Stomatologija 7, 45-47.

Macpherson, L. M., MacFarlane, T. W., Aitchison, T. C., and Stephen, K. W. (1990). The effect of sucrose application and implantation of mutans streptococci on the microbial composition of three-week experimental plaque-an in situ study. J. Dent. Res. 69, 1706-1711. doi: 10.1177/00220345900690110101

Macpherson, L. M., MacFarlane, T. W., Weetman, D. A., and Stephen, K. W. (1991). Comparison of the plaque microflora from natural and appliance-borne enamel surfaces. Caries Res. 25, 58-64. doi: 10.1159/000261343

Marsh, P. D. (1999). Microbiologic aspects of dental plaque and dental caries. Dent. Clin. North Am. 43, 599-614.

Marsh, P. D. (2005). Dental plaque: biological significance of a biofilm and community life-style. J. Clin. Periodontol. 32(Suppl. 6), 7-15. doi: 10.1111/j.1600-051X.2005.00790.x

McBain, A. J. (2009). Chapter 4: in vitro biofilm models: an overview. Adv. Appl. Microbiol. 69, 99-132. doi: 10.1016/S0065-2164(09)69004-3

Melo, M. A., Weir, M. D., Rodrigues, L. K., and Xu, H. H. (2013). Novel calcium phosphate nanocomposite with caries-inhibition in a human in situ model. Dent. Mater. 29, 231-240. doi: 10.1016/j.dental.2012.10.010

Minah, G. E., and Chu, N. (1984). Sucrose metabolism in situ by dental plaque in appliance-borne bovine enamel tooth fissure inserts in man. Arch. Oral Biol. 29 467-471. doi: 10.1016/0003-9969(84)90028-1 
Mulrow, C., Langhorne, P., and Grimshaw, J. (1997). Integrating heterogeneous pieces of evidence in systematic reviews. Ann. Intern. Med. 127, 989-995. doi: 10.7326/0003-4819-127-11-199712010-00008

Nascimento, C., Pita, M. S., Fernandes, F. H., Pedrazzi, V., de Albuquerque, R. F. Jr., and Ribeiro, R. F. (2014). Bacterial adhesion on the titanium and zirconia abutment surfaces. Clin. Oral Implants Res. 25, 337-343. doi: 10.1111/clr.12093

Netuschil, L., Reich, E., Unteregger, G., Sculean, A., and Brecx, M. (1998). A pilot study of confocal laser scanning microscopy for the assessment of undisturbed dental plaque vitality and topography. Arch. Oral Biol. 43, 277-285. doi: 10.1016/S0003-9969(97)00121-0

Newman, H. N., and Wilson, M. A. (1999). "Dental plaque revisited: oral biofilms in health and disease," in Proceedings of a Conference Held at the Royal College of Physicians London 3-5 November, 1999 (Cardiff: BioLine).

Nobbs, A. H., Lamont, R. J., and Jenkinson, H. F. (2009). Streptococcus adherence and colonization. Microbiol. Mol. Biol.Rev. 73, 407-450 doi: 10.1128/ MMBR.00014-09

Nyvad, B., and Fejerskov, O. (1987a). Scanning electron microscopy of early microbial colonization of human enamel and root surfaces in vivo. Scand. J. Dent. Res. 95, 287-296.

Nyvad, B., and Fejerskov, O. (1987b). Transmission electron microscopy of early microbial colonization of human enamel and root surfaces in vivo. Scand. J. Dent. Res. 95, 297-307.

Nyvad, B., and Fejerskov, O. (1989). Structure of dental plaque and the plaqueenamel interface in human experimental caries. Caries Res. 23, 151-158. doi: $10.1159 / 000261169$

Nyvad, B., and Kilian, M. (1987). Microbiology of the early colonization of human enamel and root surfaces in vivo. Scand. J. Dent. Res. 95, 369-380. doi: 10.1111/j.1600-0722.1987.tb01627.x

Ostrom, C. A., and Koulourides, T. (1976). The intraoral cariogenicity test in young subjects. Caries Res. 10, 442-452. doi: 10.1159/000260236

Padovani, G. C., Fucio, S. B., Ambrosano, G. M., Correr-Sobrinho, L., and PuppinRontani, R. M. (2015). In situ bacterial accumulation on dental restorative materials. CLSM/COMSTAT analysis. Am. J. Dent. 28, 3-8.

Paes Leme, A. F., Bellato, C. M., Bedi, G., Cury, A. A., Koo, H., and Cury, J. A. (2008). Effects of sucrose on the extracellular matrix of plaque-like biofilm formed in vivo, studied by proteomic analysis. Caries Res. 42, 435-443. doi: $10.1159 / 000159607$

Paes Leme, A. F., Dalcico, R., Tabchoury, C. P., Del Bel Cury, A. A., Rosalen, P. L., and Cury, J. A. (2004). In situ effect of frequent sucrose exposure on enamel demineralization and on plaque composition after APF application and F dentifrice use. J. Dent. Res. 83, 71-75. doi: 10.1177/154405910408300114

Palmer, R. J. Jr. (2010). Supragingival and subgingival plaque: paradigm of biofilms. Compend. Contin. Educ. Dent. 31, 104-106, 108, 110.

Palmer, R. J. Jr., Gordon, S. M., Cisar, J. O., and Kolenbrander, P. E. (2003). Coaggregation-mediated interactions of streptococci and actinomyces detected in initial human dental plaque. J. Bacteriol. 185, 3400-3409. doi: 10.1128/JB.185.11.3400-3409.2003

Palmer, R. J. Jr., Wu, R., Gordon, S., Bloomquist, C. G., Liljemark, W. F., Kilian, M., et al. (2001). Retrieval of biofilms from the oral cavity. Meth. Enzymol. 337, 393-403. doi: 10.1016/S0076-6879(01)37028-3

Pan, P., Barnett, M. L., Coelho, J., Brogdon, C., and Finnegan, M. B. (2000). Determination of the in situ bactericidal activity of an essential oil mouthrinse using a vital stain method. J. Clin. Periodontol. 27, 256-261. doi: 10.1034/j.1600051x.2000.027004256.x

Pecharki, G. D., Cury, J. A., Paes-Leme, A. F., Tabchoury, C. P., Del Bel Cury, A. A., Rosalen, P. L., et al. (2005). Effect of sucrose containing iron (II) on dental biofilm and enamel demineralization in situ. Caries Res. 39, 123-129. doi: $10.1159 / 000083157$

Pessan, J. P., Silva, S. M., Lauris, J. R., Sampaio, F. C., Whitford, G. M., and Buzalaf, M. A. (2008). Fluoride uptake by plaque from water and from dentifrice. J. Dent. Res. 87, 461-465. doi: 10.1177/154405910808700501

Pierro, V. S., Ferreira Dde, C., de Jesus, H. E., Rosado, A. S., Luiz, R. R., dos Santos, K. R., et al. (2013). Topical effect of a medically prescribed pediatric antibiotic on dental biofilm: a cross-over, in situ study. PLoS ONE 8:e55558. doi: 10.1371/journal.pone.0055558

Prada-López, I., Quintas, V., Donos, N., Suárez-Quintanilla, D., and Tomás, I. (2015a). Characteristics of in situ oral biofilm after 2 and 4 days of evolution. Quintessence Int. 46, 287-298. doi: 10.3290/j.qi.a33402
Prada-López, I., Quintas, V., and Tomás, I. (2015b). The intraoral device of overlaid disk-holding splints as a new in situ oral biofilm model. J. Clin. Exp. Dent. 7, e126-e132. doi: 10.4317/jced.52093

Quintas, V., Prada-López, I., Donos, N., Suárez-Quintanilla, D., and Tomás, I. (2015a). Antiplaque effect of essential oils and $0.2 \%$ chlorhexidine on an in situ model of oral biofilm growth: a randomised clinical trial. PLOS ONE 10:e0117177. doi: 10.1371/journal.pone.0117177

Quintas, V., Prada-López, I., Prados-Frutos, J. C., and Tomás, I. (2015b). In situ antimicrobial activity on oral biofilm: essential oils vs. $0.2 \%$ chlorhexidine. Clin. Oral Investig. 19, 97-107. doi: 10.1007/s00784-014-1224-3

Rasperini, G., Maglione, M., Cocconcelli, P., and Simion, M. (1998). In vivo early plaque formation on pure titanium and ceramic abutments: a comparative microbiological and SEM analysis. Clin. Oral Implants Res. 9, 357-364. doi: 10.1034/j.1600-0501.1996.090601.x

Re, D., Pellegrini, G., Francinetti, P., Augusti, D., and Rasperini, G. (2011). In vivo early plaque formation on zirconia and feldspathic ceramic. Minerva Stomatol. $60,339-348$.

Rehman, A., Hu, J., Ott, S. J., and Grossner-Schreiber, B. (2012). Microbial community composition on modified dental implant surfaces: an in vivo study. Int. J. Oral Maxillofac. Implants 27, 811-819. doi: 10.1111/j.16000501.2009.01729.x

Ribeiro, C. C., Tabchoury, C. P., Del Bel Cury, A. A., Tenuta, L. M., Rosalen, P. L., and Cury, J. A. (2005). Effect of starch on the cariogenic potential of sucrose. Br. J. Nutr. 94, 44-50. doi: 10.1079/BJN20051452

Rimondini, L., Fare, S., Brambilla, E., Felloni, A., Consonni, C., Brossa, F., et al. (1997). The effect of surface roughness on early in vivo plaque colonization on titanium. J. Periodontol. 68, 556-562. doi: 10.1902/jop.1997.68.6.556

Robinson, C., Kirkham, J., Percival, R., Shore, R. C., Bonass, W. A., Brookes, S. J., et al. (1997). A method for the quantitative site-specific study of the biochemistry within dental plaque biofilms formed in vivo. Caries Res. 31, 194-200. doi: 10.1159/000262398

Robinson, C., Strafford, S., Rees, G., Brookes, S. J., Kirkham, J., Shore, R. C., et al. (2006). Plaque biofilms: the effect of chemical environment on natural human plaque biofilm architecture. Arch. Oral Biol. 51, 1006-1014. doi: 10.1016/j.archoralbio.2006.04.010

Rosin, M., Welk, A., Kocher, T., Majic-Todt, A., Kramer, A., and Pitten, F. A. (2002). The effect of a polyhexamethylene biguanide mouthrinse compared to an essential oil rinse and a chlorhexidine rinse on bacterial counts and 4-day plaque regrowth. J. Clin. Periodontol. 29, 392-399. doi: 10.1034/j.1600051X.2002.290503.x

Rupf, S., Balkenhol, M., Sahrhage, T. O., Baum, A., Chromik, J. N., Ruppert, K., et al. (2012). Biofilm inhibition by an experimental dental resin composite containing octenidine dihydrochloride. Dent. Mater. 28, 974-984. doi: 10.1016/j.dental.2012.04.034

Scarano, A., Piattelli, M., Vrespa, G., Caputi, S., and Piattelli, A. (2003). Bacterial adhesion on titanium nitride-coated and uncoated implants: an in vivo human study. J. Oral Implantol. 29, 80-85. doi: 10.1563/15481336(2003)029\&lt;0080:BAOTNA\&gt;2.3.CO;2

Schwarz, F., Ferrari, D., Popovski, K., Hartig, B., and Becker, J. (2009). Influence of different air-abrasive powders on cell viability at biologically contaminated titanium dental implants surfaces. J. Biomed. Mater. Res. B Appl. Biomater. 88, 83-91. doi: $10.1002 / j b m . b .31154$

Schwarz, F., Nuesry, E., Bieling, K., Herten, M., and Becker, J. (2006). Influence of an erbium, chromium-doped yttrium, scandium, gallium, and garnet (Er,Cr:YSGG) laser on the reestablishment of the biocompatibility of contaminated titanium implant surfaces. J. Periodontol. 77, 1820-1827. doi: 10.1902/jop.2006.050456

Schwarz, F., Sculean, A., Wieland, M., Horn, N., Nuesry, E., Bube, C., et al. (2007). Effects of hydrophilicity and microtopography of titanium implant surfaces on initial supragingival plaque biofilm formation. A pilot study. Mund Kiefer und Gesichtschirurgie 11, 333-338. doi: 10.1007/s10006-0070079-z

Scotti, R., Kantorski, K. Z., Monaco, C., Valandro, L. F., Ciocca, L., and Bottino, M. A. (2007). SEM evaluation of in situ early bacterial colonization on a Y-TZP ceramic: a pilot study. Int. J. Prosthodont. 20, 419-422.

Sennhenn-Kirchner, S., Klaue, S., Wolff, N., Mergeryan, H., Borg von Zepelin, M., and Jacobs, H. G. (2007). Decontamination of rough titanium surfaces with diode lasers: microbiological findings on in vivo grown 
biofilms. Clin. Oral Implants Res. 18, 126-132. doi: 10.1111/j.1600-0501.2006. 01298.x

Sennhenn-Kirchner, S., Wolff, N., Klaue, S., Mergeryan, H., and Borg-von Zepelin, M. (2009). Decontamination efficacy of antiseptic agents on in vivo grown biofilms on rough titanium surfaces. Quintessence Int. 40, e80-e88.

Shore, R. C., Kirkham, J., Devine, D., Marsh, P., Nattress, B., and Robinson, C. (2001). Investigation to evaluate and validate the Leeds in situ device for the study of enamel remineralisation in vivo. J. Dent. 29, 415-419. doi: 10.1016/S0300-5712(01)00033-1

Simion, M., Maglione, M., Iamoni, F., Scarano, A., Piattelli, A., and Salvato, A. (1997). Bacterial penetration through Resolut resorbable membrane in vitro. An histological and scanning electron microscopic study. Clin. Oral Implants Res. 8, 23-31. doi: 10.1111/j.1600-0501.1997.tb00004.x

Sousa, R. P., Zanin, I. C., Lima, J. P., Vasconcelos, S. M., Melo, M. A., Beltrao, H. C., et al. (2009). In situ effects of restorative materials on dental biofilm and enamel demineralisation. J. Dent. 37, 44-51. doi: 10.1016/j.jdent.2008.08.009

Sreenivasan, P. K., Furgang, D., Markowitz, K., McKiernan, M., Tischio-Bereski, D., Devizio, W., et al. (2009). Clinical anti-microbial efficacy of a new zinc citrate dentifrice. Clin. Oral Investig. 13, 195-202. doi: 10.1007/s00784-0080227-3

Sreenivasan, P. K., Mattai, J., Nabi, N., Xu, T., and Gaffar, A. (2004). A simple approach to examine early oral microbial biofilm formation and the effects of treatments. Oral Microbiol. Immunol. 19, 297-302. doi: 10.1111/j.1399302x.2004.00158.x

Strassler, H. E., Minah, G. E., and Kula, K. S. (1986). Microbiological and microhardness evaluation of artificial enamel fissures worn intraorally by humans. J. Clin. Microbiol. 23, 6-10.

Teixeira, A. H., Pereira, E. S., Rodrigues, L. K., Saxena, D., Duarte, S., and Zanin, I. C. (2012). Effect of photodynamic antimicrobial chemotherapy on in vitro and in situ biofilms. Caries Res. 46, 549-554. doi: 10.1159/000341190

Tenuta, L. M., Lima, J. E., Cardoso, C. L., Tabchoury, C. P., and Cury, J. A. (2003). Effect of plaque accumulation and salivary factors on enamel demineralization and plaque composition in situ. Pesqui. Odontol. Bras. 17, 326-331. doi: 10.1590/S1517-74912003000400006

Tomás, I., García-Caballero, L., López-Alvar, E., Suarez-Cunqueiro, M., Diz, P., and Seoane, J. (2013). In situ chlorhexidine substantivity on saliva and plaquelike biofilm: influence of circadian rhythm. J. Periodontol. 84, 1662-1672. doi: 10.1902/jop.2013.120475

van der Mei, H. C., White, D. J., Atema-Smit, J., van de Belt-Gritter, E., and Busscher, H. J. (2006). A method to study sustained antimicrobial activity of rinse and dentifrice components on biofilm viability in vivo. J. Clin. Periodontol. 33, 14-20. doi: 10.1111/j.1600-051X.2005.00859.x von Ohle, C., Gieseke, A., Nistico, L., Decker, E. M., DeBeer, D., and Stoodley, P. (2010). Real-time microsensor measurement of local metabolic activities in ex vivo dental biofilms exposed to sucrose and treated with chlorhexidine. Appl. Environ. Microbiol. 76, 2326-2334. doi: 10.1128/AEM.02090-09

Watson, P. S., Pontefract, H. A., Devine, D. A., Shore, R. C., Nattress, B. R., Kirkham, J., et al. (2005). Penetration of fluoride into natural plaque biofilms. J. Dent. Res. 84, 451-455. doi: 10.1177/154405910508400510

Wecke, J., Kersten, T., Madela, K., Moter, A., Gobel, U. B., Friedmann, A., et al. (2000). A novel technique for monitoring the development of bacterial biofilms in human periodontal pockets. FEMS Microbiol. Lett. 191, 95-101. doi: 10.1111/j.1574-6968.2000.tb09324.x

Wood, S., Nattress, B., Kirkham, J., Shore, R., Brookes, S., Griffiths, J., et al. (1999). An in vitro study of the use of photodynamic therapy for the treatment of natural oral plaque biofilms formed in vivo. J. Photochem. Photobiol. B Biol. $50,1-7$.

Wood, S. R., Kirkham, J., Marsh, P. D., Shore, R. C., Nattress, B., and Robinson, C. (2000). Architecture of intact natural human plaque biofilms studied by confocal laser scanning microscopy. J. Dent. Res. 79, 21-27. doi: $10.1177 / 00220345000790010201$

Wood, S. R., Kirkham, J., Shore, R. C., Brookes, S. J., and Robinson, C. (2002). Changes in the structure and density of oral plaque biofilms with increasing plaque age. FEMS Microbiol. Ecol. 39, 239-244. doi: 10.1111/j.15746941.2002.tb00926.x

Zucchelli, G., Cesari, C., Clauser, C., and DeSanctis, M. (1998). Early bacterial accumulation on guided tissue regeneration membrane materials. An in vivo study. J. Periodontol. 69, 1193-1202. doi: 10.1902/jop.1998.69.11.1193

Zucchelli, G., Pollini, F., Clauser, C., and De Sanctis, M. (2000). The effect of chlorhexidine mouthrinses on early bacterial colonization of guided tissue regeneration membranes. An in vivo study. J. Periodontol. 71, 263-271. doi: 10.1902/jop.2000.71.2.263

Conflict of Interest Statement: The authors declare that the research was conducted in the absence of any commercial or financial relationships that could be construed as a potential conflict of interest.

Copyright (® 2016 Prada-López, Quintas, Vilaboa, Suárez-Quintanilla and Tomás. This is an open-access article distributed under the terms of the Creative Commons Attribution License (CC BY). The use, distribution or reproduction in other forums is permitted, provided the original author(s) or licensor are credited and that the original publication in this journal is cited, in accordance with accepted academic practice. No use, distribution or reproduction is permitted which does not comply with these terms. 